\title{
DE NUEVO SOBRE LA LECTURA DE LA ESCRITURA MONUMENTAL TARTESIA O SUDLUSITANA
}

\section{ANOTHER LOOK AT THE TRANSLITERATION OF THE TARTESSIAN (OR SOUTH-LUSITANIAN) MONUMENTAL SCRIPT}

Jesús Rodríguez Ramos

jrr_ib@hotmail.com

DOI: $10.1387 /$ veleia.14983

Resumen: En este artículo se revisan algunos problemas concretos de la lectura de la escritura de las estelas llamadas tartesias a partir de las novedades epigráficas de los últimos años. Los principales puntos analizados son cuatro: 1) una revisión de la variante algarveña de la escritura, en concreto sobre el uso de signos en forma de «heth» para la letra $\mathbf{t}^{\mathbf{a}}$; 2) el nuevo apoyo a mi propuesta de lectura sobre los signos $\mathbf{k}^{\mathrm{u}}$ y $\mathrm{p}^{\mathrm{u}}$; 3) las novedades sobre la certeza en la existencia de un cuarto signo asociado a la vocal $\mathbf{u} ; 4)$ una revisión sobre el problema de la notación o no del fonema $/ \mathrm{m} /$ en la escritura, tanto tomando en cuenta los signos similares a $\mathbf{n}$ y a la «my» griega, como al posible valor digráfico de los grupos np, sea para representar $/ \mathrm{m} /$ o para otro valor.

Palabras clave: escritura tartesia, escritura sudlusitana, escrituras paleohispánicas, Tartesos, Epigrafía paleohispánica.

Abstract: This paper revises some particular questions regarding the reading of the script in the steles called Tartessian in light of recent epigraphic discoveries. Four main points are suggested: 1) revision of the Algarvian variant of the script, specifically on the use of signs in the shape of "heth» for the letter $\mathbf{t}^{\mathrm{a}} ; 2$ ) new support for my proposal on the reading of $\mathbf{k}^{\mathbf{u}}$ and $\mathrm{p}^{\mathbf{u}}$; 3) new evidence for the existence of a fourth sign connected to the vowel $\mathbf{u}$; 4) revision of the problem of whether there was or not some method of notation of the phoneme $/ \mathrm{m} / \mathrm{in}$ the script, taking into account the signs similar to both the $\mathbf{n}$ and the Greek 'my', as well as the possible digraphical value of the groups $n p$ to represent either $/ \mathrm{m} /$ or another sound.

Keywords: Tartessian script, South-Lusitanian script, Palaeohispanic scripts, Tartessos, Palaeohispanic Epigraphy.

Recibido: 13-10-2014

Informado: 02-12-2014

Definitivo: 05-02-2015

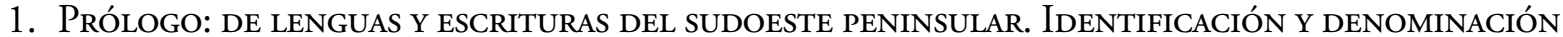

Este artículo consiste en una revisión de mis trabajos anteriores sobre la decodificación de la escritura sudlusitana a la luz de la nueva evidencia disponible, las modificaciones que suponen y las nuevas posibilidades que plantea. 
Pero antes de entrar en materia cabe hacer una consideración sobre el nombre de la escritura y la lengua de las estelas. En los últimos años la denominación estándar es la de "tartesia». Esto probablemente se ha visto favorecido por criterios subjetivos no científicos: es un nombre que llama más la atención y «vende» más. Pero objetivamente es una denominación dudosa. En la zona nuclear tartesia, entendiendo tanto la que arqueológicamente es la zona orientalizante tartesia, como el territorio que las fuentes antiguas consideran tartesio (que debiera ser el criterio), la presencia de esta escritura es muy reducida, mientras que los testimonios son abundantes en zonas periféricas.

De acuerdo con las fuentes clásicas hace tiempo que se viene considerando que el extremo sur de Portugal (donde se concentra el mayor número de las inscripciones) corresponde a los kynetes / kynesios, pueblo que las fuentes diferencian claramente de los tartesios. Recientemente Almagro (2008) ha reivindicado que la zona del Guadiana en Extremadura sería también territorio kynete y Medellín su capital (Conisturgis). A decir verdad, no veo que la argumentación de Almagro demuestre realmente que Medellín sea Conisturgis, pero lo hace verosímil por su razonamiento. De un lado por molestarse en revisar las fuentes, que indican que los kynetes también habitan por el Guadiana (sin más precisiones); de otro por relacionarlo con los paralelismos arqueológicos entre la zona de Medellín y algunas necrópolis del sur de Portugal, que son bastante concretos.

Es por ello que, si tuviéramos que usar una denominación étnica, tendríamos que usar una denominación del tipo kynete, kynesia, cinética, conia o similar, remarcando que las fuentes diferencian entre kynetes y tartesios; pero el término «tartesio» es el estándar de facto.

Así las cosas, para no mezclar conceptos indebidamente, sugiero como solución de compromiso las denominaciones «escritura monumental tartesia» y "tartésico monumental», aprovechando que parece poco probable que empecemos a encontrar inscripciones sobre edificios o monumentos en los yacimientos del área propiamente tartesia. Por motivos técnicos e historiográficos personalmente sigo prefiriendo la denominación de sudlusitano que precisamente le dio en 1961 el descifrador de esta escritura, Ulrich Schmoll.

En todo caso, la denominación de escritura monumental tartesia tiene ventajas objetivas, pues enfatiza su idiosincrasia como una tradición epigráfica propia. Se sabe que los grafitos cerámicos orientalizantes del sudoeste peninsular, de yacimientos propiamente tartesios y de su periferia, son diferentes y presentan dificultades de lectura y diferencias notables respecto a la escritura de las estelas. Esta diferencia ya ha sido apuntada en diversas ocasiones: por ejemplo, hace años por Correa (1992, 79s), y recientemente De Hoz (2010, 367), llamando la atención sobre el hecho de que en la escritura de los grafitos no se encuentre la redundancia vocálica, ha apuntado que quizás la escritura de las estelas sea arcaizante o una escritura «ceremonial». Tal vez pudiéramos diferenciar las inscripciones de los grafitos llamándolas tartésico «demótico».

En el mismo sentido es pertinente recordar que desde hace años De Hoz viene considerando que ha de existir otra escritura realmente tartesia, en especial al tratar el tema del origen de la escritura y al considerar el signario de Espanca como escritura tartesia y diferente a la de las estelas (De Hoz 1990, 242). Evidentemente, el problema para esto es la falta de definición de lo que sería esa escritura tartesia.

Con todo, durante la redacción de este artículo se ha publicado un nuevo grafito que podría variar o matizar esta perspectiva. Del grafito 1 de Niebla (Toscano y Correa 2014, 50s) solo se conserva una pequeńa parte, pero leyendo según el signario monumental tartesio una de las lecturas más plausibles de lo que se conserva es ] op ${ }^{\mathbf{e}}$ are[. Correa, quien sugiere algunas alternativas, no ve problema a una lectura opeare con un signo de e delante de a por lo indicado de que el fenómeno 
de la redundacia vocálica parece exclusivo de las estelas; pero, por el motivo que sea, no ha explicitado la otra posibilidad obvia.

Consideremos los siguientes factores: 1) que precisamente esa forma del tartesio monumental de pe es la forma que se utiliza en íbero meridional para el silabograma ba; 2) que en la escritura monumental tartesia se encuentran casos de aparente simplificación del signario en que se usa un mismo signo para a y e en vez de uno diferente para cada vocal; 3) la existencia de una inscripción cerámica de Medellín (Untermann 1997, 103 n. ${ }^{\circ}$ 14) donde tendríamos los dos mismos signos, con forma de «pi» arcaica y de «alpha».

Dados estos considerandos, podemos plantear a modo de hipótesis que este signo tuviera en estos grafitos realmente el valor de pa y que la incómoda secuencia de signo silábico seguido de vocal fuese en realidad redundancia vocálica. De esta manera el grafito de Medellín se leería pa (o $\mathbf{p}^{\mathbf{a}} \mathbf{a}$ en notación larga) mientras que el de Niebla se leería ]opare[. En tal caso sería llamativa la coincidencia con la fórmula de las estelas te-ero-pare y sería tanto un indicio para suponer que efectivamente la lengua sea la misma, como también, al haber coincidencia en dos tipos de soporte diferentes, para sospecharle un sentido de acción del dedicante (preferiblemente votivo, tipo

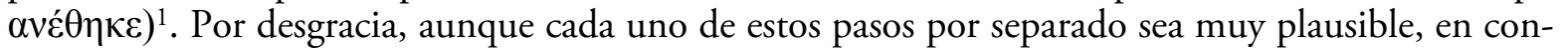
junto suman una incerteza excesiva.

Pero aparte del testimonio discordante de los grafitos, merece tenerse en cuenta el que más allá del testimonio epigráfico sí que existe un argumento lingüístico que podría apoyar el que la lengua de las incripciones de la zona kyneta (básicamente las estelas) fuese la misma o similar a la de la zona turdetana. Es un aspecto del análisis de la toponimia meridional efectuado por Correa (2002) al que se le ha prestado poca atención. Su estudio concluye que los topónimos indígenas presentan una serie de marcadas restricciones en su estructura fonética y que estas restricciones se encuentran en toda la zona meridional, apuntando pues a una unidad lingüística. Es cierto que el testimonio es unos siglos posterior a las inscripciones, es cierto que hay una molesta irregularidad en el muestreo que le resta contundencia estadística (pues de unas regiones se conocen muchos más topónimos, mientras que de otras, entre ellas el sur de Portugal, muchos menos), pero es un argumento real y objetivo a favor de una cierta unidad lingüística en la Bética. Para mí es llamativo también el que haya una preponderancia vocálica de /a/, frente a una escasez del vocalismo /e/, en la primera sílaba tanto de los topónimos meridionales como en las estelas ${ }^{2}$.

Por otra parte, dejando de lado las incómodas modas según las cuales para algunos investigadores la inmensa mayoría de los grafitos orientalizantes serían indígenas paleohispánicos (incluso algunos de claro aspecto fenicio), mientras que para otros prácticamente no existiría grafito cerámico orientalizante que no fuese fenicio (pese a que tengan que «forzar» la paleografía de las piezas) ${ }^{3}$,

1 Para cuestiones de combinatoria, segmentación y posibles significados me remito a Rodríguez Ramos 2005-2009. He de reconocer que cuando lo terminé (enero de 2005) no me imaginaba que las viejas ideas que recogía de mi tesis de licenciatura (Rodríguez Ramos 1992, 394-400; pero véase también 2002a, 94, nota 7) se encontrarían ahora de rabiosa actualidad en algunas universidades, y menos que se hicieran con menos auto-crítica que incluso mi 1992 (del cual no era precisamente la parte más lograda).
2 Rodríguez Ramos 2002a, 90s; 2005-2009, 95. Para los topónimos me baso también en un cotejo adicional a partir de los topónimos meridionales listados por De Hoz 2010, 322-327.

3 Una revisión bastante equilibrada en De $\mathrm{Hoz}$ 2010, 361-368. Como indica De Hoz algunos grafitos pueden adscribirse en ambos sentidos. Para el que comenta en nota 387, la hipótesis fenicia me parece más probable por la paleografía del «teth», que como e paleohispánica parecería demasiado moderna. 
hace tiempo que indiqué que el principal testimonio epigrafíco de la zona tartesia / turdetana es fenicio y púnico ${ }^{4}$. Es evidente que este fenómeno no ha recibido la atención que merece.

En mi opinión debiéramos plantearnos la posibilidad de un fuerte mestizaje cultural con una progresiva cananización de la zona tartesia, de forma similar a lo que señalan las fuentes romanas sobre que los turdetanos se romanizaron de forma muy rápida en costumbres y lengua. Quizás desde un principio la zona del bajo Guadalquivir tartesio fuese multi-étnica y por ello se acomodase a las sucesivas lenguas de prestigio y administrativas. Es posible que la escritura e incluso la lengua fenicia haya tenido un uso dentro de la cultura indígena. Es posible incluso que la presencia residual de las estelas escritas (que es un ítem cultural ritual claro) en la zona propiamente tartesia, tenga que ver con que la práctica cultural de las estelas (previamente anepígrafas decoradas, modelo alemtejanas o extremeñas) hubiese sido desplazada rápidamente por otros modelos orientalizantes 5 . Tal vez también se relacione con esto la existencia de las cecas neo-púnicas irregulares llamadas «libio-fenices» ${ }^{6}$.

\section{La escritura monumental tartesia (sudlusitana)}

Sea como resultare ser, en este artículo nos centraremos en la escritura "monumental tartesia» que constituye una epigrafía básicamente sobre estelas cuyos ejemplares se concentran en el Algarve y el Bajo Alemtejo, con un núcleo mucho menor en la zona del Guadiana extremeño y algunos casos aislados en el Guadalquivir. Epigrafía para la que parece que sigue siendo válida la conclusión de mi tesina de que se usaría al menos en los ss. vI-v, con un claro uso en el s. v, pero sin poder asegurarse su uso en el s. vir (Rodríguez Ramos 1992, 73; 2002a, 87; 2002a, 87). Este conjunto epigráfico pertenece a una escritura alfabética de clara adscripción paleohispánica (similar a la íbera meridional) y se caracteriza por el fenómeno de la redundancia vocálica. Con todo, estas inscripciones no presentan una unidad paleográfica ni sistémica completa; existiendo variantes geográficas.

Desde mi último estudio publicado sobre esta escritura, ha habido novedades epigráficas significativas. Aunque los trabajos sobre el tema no es que hayan escaseado precisamente, sí que cabe lamentar que la mayoría no se hayan preocupado del análisis interno y que en algunos casos las lecturas asignadas a los signos se basen en un estudio parcial de los datos o incluso en criterios sub-

4 Rodríguez Ramos 1992, 298. Donde también indico que puede plantearse que no se debe exclusivamente a la "presencia demográfica semita» y recuerdo que una adopción de usos epigráficos fenicios produce precisamente la pérdida de inscripciones por hacerse sobre materiales perecederos. Aunque aquí me refería a papiro, no está de más recordar que el ductus de los signos meridionales sugiere el uso de madera como soporte epigráfico (Rodríguez Ramos 2001,19).

5 Naturalmente otra explicación podría ser que correspondiera a la presencia de minorías étnicas «kynetes» en la zona o a una dicotomía población agrícola/ urbana innovadora frente a ganadera/trashumante conservadora.

6 Aunque en algunas fuentes clásicas el término libio-fenice parece estar en su sentido literal «púnicos de África», en Pseudo-Escimno se define claramente como parte de una colonización cartaginesa en la costa andaluza mediterránea. La relación que guarden las cecas nominadas por los numísmatas "libio-fenices» (más bien atlánticas) con ese fenómeno no es algo seguro. Es interesante la idea que desde hace años viene desarrollando García-Bellido (2008) de verlas como indicio de algún tipo de colonización cartaginesa, recientemente como cleruquías de mercenarios, en un intento evidente de solucionar el problema de por qué unas colonias cartaginesas elaborarían una variante de escritura propia. Tal vez una explicación sencilla tenga que ver con la deserción de estos núcleos pasándose a los romanos, implicando una voluntad de distanciamiento político e incluso un cambio en el grupo dirigente. De todas maneras, el nombre turdetano de algunas de estas cecas apunta a algún tipo de origen indígena de dichos núcleos. 
jetivos. Dentro de dicha superficialidad tengo que advertir contra lo muy mal resumidas y glosadas que en ocasiones han sido mis propuestas, remitiendo al lector a los originales ${ }^{7}$.

Entrando en materia, la presente revisión se articula siguiendo los siguientes aspectos ${ }^{8}$ :

2.1. Una revisión de la propuesta de existencia de una dicotomía de subsignarios entre el del Algarve y el de las otras zonas; centrada en el signo ta.

2.2. La aparición de dos segmentos paralelos en una misma inscripción que constituye un apoyo a mi propuesta sobre los signos $\mathbf{p} \mathbf{u}^{9}$ y $\mathbf{k u}$.

2.3. La refutación de mi intento de simplificación de las variedades de signos silabicos ante $\mathbf{u}$. La aparición por primera vez juntos de los signos $\mathbb{W}$ y en una misma inscripción y ambos en uso regular (ante $\mathbf{u}$ ) hace que tengamos que contar con cuatro signos de la serie $\mathbf{u}^{10}$

2.4. Revisión del problema de si existía o no notación de un sonido $/ \mathrm{m} /$ en tartésico monumental.

Los dos primeros aspectos son más sencillos y de menor recorrido. Los dos segundos tienen más implicaciones y podrían estar interrelacionados. Por un lado tenemos una serie de signos «sobrantes» en el sistema cuya forma recuerda a n o a la «mem» fenicia post-arcaica o la «my» griega. Para estos signos, que por mor de la exposición llamaré «muoides», hace ya muchos años que Correa planteó la posibilidad de una cuarta serie silábica de timbre $/ \mathrm{m} /$.

En mi tesis de licenciatura (1992, 280s) investigué expresamente las posibilidades hermenéuticas de una cuarta serie de silabogramas, tanto considerando el planteamiento de Correa de una serie labial nasal, como la posibilidad alternativa de una serie de aspiradas. En ese análisis planteaba también los inconvenientes que presentaban estos modelos cuatripartitos y me decantaba por una modificación mínima del sistema tripartito como solución más probable.

Ahora bien, parte de la solución radicaba en que el signo muoide que aparece ante u nunca coincidía con el signo ku y en su ligero parecido formal con él. Mi propuesta era considerar que ambos signos fuesen variantes alográficas. La nueva evidencia, mostrando su coexistencia, hace preciso revisar la problemática de los signos muoides.

Adicionalmente, dado este considerando, resulta interesante la evaluación de una serie sospechosamente alta de «coincidencias» gráficas -np- y «alternancias» -np- / -p-, por la posibilidad de que sea un recurso para notar una marca nasal sobre una labial. Es decir: $/ \mathrm{m} /$.

\subsection{Dicotomia de signarios}

Como definí en Rodríguez Ramos (1992, 193s; mapas 11-13) el sistema de escritura de las estelas presenta una diferencia clara regional en la que, además de algunas variantes concretas de las formas de signos como te y de pu, la principal diferencia corresponde al signo ta.

7 P. ej. Guerra 2002, 226, aunque me cita en la bibliografía, me atribuye una lectura del signo $\boldsymbol{Y}$ que no solo no he propuesto nunca, sino que es incompatible con mis propuestas. Comprobar que el error coincide con una errata en el cuadro resumen de Untermann 1997,153 aclara el misterio etiológico aunque plantea otras incógnitas.

8 No entro a detallar el conjunto de los criterios metodológicos de análisis propios de la decodificación de esta escritura. En caso necesario el lector puede remitirse a Rodríguez Ramos 2000a.

9 Por considerarlo más objetivo, me aparto en este artículo de la notación tradicional paleohispánica iberista como /b/ de la oclusiva labial, que por defecto he solido emplear.

10 Importante detalle no apreciado en su publicación, aunque sí en De Hoz 2010, 377, nota 440 y Rodríguez Ramos 2005-2009, 86, nota 7. 
Es bien conocido que la forma típica paleohispánica de ta $X$ derivada del «taw» fenicio, se usa como pseudo-silabograma fijo ante a; pero el análisis de la distribución geográfica mostraba que, en una zona que coincide básicamente con la actual provincia del Algarve, esta forma no aparecía en ninguna inscripción conservada. En cambio, en esta zona delante de a se documentaba una presencia de formas similares al fenicio «heth» exclusiva de esta zona y, por tanto, en distribución complementaria (Rodríguez Ramos 1992, 193; mapas 6 y 11; 2000, 36ss). A eso se sumaba el que las formas de "heth» ante e son la forma regular de te y que en la zona algarveña hay incluso alguna inscripción en que la misma forma "heth» se usa tanto ante e como ante a (como en la famosa J.1.1).

Lo que plantean estos hechos es obvio: en esta zona para notar ta se utilizan las formas tipo «heth» y (dado que la forma más extendida se relaciona con el «taw» fenicio) sería una innovación del signario de esta zona creando un nuevo diagrapto ${ }^{11}$. Esta innovación partiría de asimilar la forma del signo te a usos para ta. Por ello no sería raro el único caso en que parece existir un $\mathbf{X}$, sino que lo llamativo es que no aparezca una serie de inscripciones previas a la innovación en la zona.

Las nuevas inscripciones amplían la evidencia: presentan la forma normal «taw» las de Mesas do Castelinho (Guerra 1999) y Monte Gordo (Guerra 2013), mientras que la forma de «heth» se encuentra en la de San Martinho (Guerra 2002). Son las tres que tienen una cierta extensión y respetan tanto el no coincidir ambas soluciones en una misma inscripción, como la distribución regional complementaria.

Sin embargo, hay una cuestión concerniente. En mi análisis inicial, dentro de la búsqueda de simplificaciones o «hiperregularizaciones» del signario, analizaba la presencia de la forma rectangular $\mathbf{Z}$ ante a como un posible uso de po y, por lo tanto, como una especie de $\mathbf{p}(\mathbf{o}) \mathbf{a} / \mathbf{p}^{\mathbf{o}} \mathbf{a}$ (Rodríguez Ramos 1992, 259 y 265). Un apoyo a esta idea era la lectura resultante del microfragmento de J.6.2 como ] pare [ con abundantes paralelos. Pero el signo que leía como r (hápax S-310) ha sido razonablemente relacionado por Correa (1987, 278 y 1992, 92), seguido en esto por Correia y Untermann, como una variante de be, pareciendo una interpretación preferible. Además, hay que tener en cuenta que las relaciones formales entre signos parecen ser respectivamente entre formas que preceden a a y e, y entre formas ante $\mathbf{o}$ y $\mathbf{u}$, lo que hace menos probable la relación con po. A esta argumentación, ya de por sí adecuada, hay que añadir que en la inscripción de S. Martinho se encuentra la forma normal de pa junto a una forma rectángulo usada tanto ante e como ante a. Por ello, hay que considerar las apariciones de formas rectangulares $\mathbf{Z}$ ante a como formas de «heth».

Consecuentemente hay que ańadir la estela de Mértola J.28.1, que es claramente septentrional, al listado de usos de "heth» ante a. Como la inscripción es un tanto extraña en disposición y en alguno de sus signos, y además está muy fragmentada, podría suponerse algún signario especial aparte, o suponerse que, dado que Mértola era un puerto fluvial antiguo con conexión directa al mar, este centro tuviera una especial relación con el sur. Es posible, y la segunda idea es interesante, pero no conviene contentarse con explicaciones «ad hoc», ni creo que sea necesario. Repasemos la evidencia.

La forma de "heth» (incluida la rectangular) se encuentra ante a en las inscripciones de los siguientes sitios: Fonte Velha (J.1.1 y J.1.4), Dobra (J.3.1), Alagóa (J.6.2), Vale dos Vermelhos (J.7.1), Mestras (J.10.1), Tavilhão (J.11.1), Mértola (J.28.1) y S. Martinho (Guerra 2002).

11 Uso el término «diagrapto» como variante dentro de una escritura, de mismo modo que un «dialecto» lo es de un idioma. 
Por su parte, la forma en aspa ante a se encuentra en Abóbada (J.12.1), Alcoforado (J.14.1), Fonte Santa (J.16.4), Herdade do Pego (J.19.1), Gaviáo (J.26.1), Capote (J.54.1), Siruela (J.55.1), Mesas do Castelinho, Monte Gordo y probablemente en la de Alcalá del Río (J.53.1) conocida solo por diversos dibujos.

Indico aparte los dos únicos casos meridionales en que podríamos tener la forma en aspa. Estos son J.4.1 (Benaciate) y J.1.6. En el primer caso tenemos una estela amplia pero solo conocida por una fotografía. La fotografía es muy buena y, aunque la zona donde estaría el aspa no se ve especialmente bien, parece que, salvo que coincidiera con un daño en la estela, realmente tenemos un ta normal. En cambio, J.1.6 es inservible, pues es ilegible ${ }^{12}$ y no puede considerarse una estela por su reducido tamaño y grosor ${ }^{13}$.

En ninguna inscripción coincide el uso de ambas formas a la vez. Téngase en cuenta que del primer grupo no son precisamente breves J.1.1 (de 74 signos) y S. Martinho (con 56 legibles); y que en J.1.1 coexiste con tres formas ante $\mathbf{a}(\mathbf{k a}, \mathbf{p a}$ y una forma entre $\mathbf{k a}$ y $\mathbf{n}$ sobre la que hablaremos infra). Del segundo grupo (el normal con la forma en aspa) destaca la estela de Mesas do Castelinho con 82 signos legibles, donde aparece con ka y con pa, pero sin ningún caso de "heth» ante $\mathbf{a}$.

Si lo comparamos en conjunto tenemos que el uso de "heth» ante a: 1) coexiste con ka en J.1.1, J.10.1 y tal vez en J.1.4; y 2) coexiste con pa en J.1.1, J.3.1, J.10.1, J.11.1, S. Martinho.

De esta manera tenemos una fuerte coherencia geográfica, donde las formas de «heth» corresponden grosso modo al Algarve, mientras que las formas «taw» ocupan el resto del territorio, con la única irregularidad de Mértola. Tenemos también a favor el análisis interno que nos indica que ambas variantes nunca coexisten en una misma inscripción y que ambas coexisten simultáneamente con las otras dos formas del «casillero»: ka y pa. Se observa además que en la zona meridional el uso de «heth» ante a no es precisamente infrecuente u ocasional.

Este análisis interno y de dispersión geográfica bastaría para proponer que las formas de «heth» ante a y de "taw» son equivalentes, siendo ambas ta; pero tenemos datos adicionales a favor, tanto de conformación del signario, como de fonética sintáctica y contextuales.

De la configuración del signario, es relevante el que en J.1.1 y en S. Martinho se utiliza la misma variante de "heth» ante a que la que se usa para te, no formas diferentes a pesar de las múltiples pequeñas variantes que los diversos signos de «heth» presentan. Suponer que se da una simplificación del signario con un mismo signo para a y e no es un fenómeno hipotético: se documenta al menos en dos inscripciones con el signo pa tanto en su uso regular ante a como ante $\mathbf{e}$ (transcrito como $\mathbf{p}^{\mathbf{a}} \mathbf{e}$ ): J.7.8 ...te $\mathbf{p}^{\mathrm{a} e r e}$ naŕken... ea iupa y J.12.4 ] $\mathbf{p}^{\mathrm{a}}$ epalaki...

De fonética sintáctica ya en Rodríguez Ramos $(2000,37)$ indiqué que la combinatoria de los signos sibilantes ante consonante era muy limitada, encontrándose solo ante $\mathbf{n}$ y ante t; siendo la única excepción el grupo más complejo arskeir de J.11.5. Esta limitación de combinatoria persiste en las nuevas inscripciones donde tenemos: paste (S. Martinho) y kasta (Mesas do Castelinho). Pues bien, resulta que esta combinatoria aparentemente exclusiva también se produce ante los signos en «heth» ante a (leyéndolos como t): aśtapo y aśtana (J.7.1) ${ }^{14}$.

12 En la lectura que propone Untermann de los dos signos que da como a, uno tiene forma de $\mathbf{l}$ y el otro de a sí, pero de a levantina, no tartesia. En el mejor de los casos habría que añadirlo al corpus de grafitos indescifrables.

13 No se entiende bien que Untermann clasificase como no estela la pieza de Azinhal (Untermann 1997,
97) por criterios de tamaño $(77 \times 38 \times 8 \mathrm{~cm})$ y no hiciese lo mismo con J.1.6 ( $8 \times 6 \times 1)$. Seguramente un lapsus.

${ }_{14}$ Para que la diversidad de sibilante no confunda, obsérvese que ya previamente estaban atestiguados \#iśt ${ }^{\mathrm{u}}$ [ en J.7.4 y ..ośta-e-pare (J.14.1) con la ta en aspa. 
En lo que concierne a los testimonios contextuales tenemos alguno interno de las inscripciones que ya indiqué en mi artículo de 2000, pero que puede ampliarse, y uno onomástico muy especulativo, pero especialmente llamativo.

En su momento comparé los segmentos que con «taw» se leen eertaune (J.55.1) y ertau\# con el final de la inscripción J.10.1 que, con la forma "heth", se leería eretau\# en J.54.1. Creo que sobre este segmento, que en la actualidad prefiero segmentar como tau, conviene hacer un repaso más exhaustivo. Aunque por las pequeñas variaciones la comparación no es decisiva, sí que es lo bastante interesante como para sospechar que tenemos un elemento repetitivo con diversas terminaciones y que por lo tanto su identificación sería un apoyo a la lectura de los «heth» ante a. Repasemos los datos.

Formas con el ta normal:

J.54.1 ]uosorertau\#. Untermann no lo considera segmento final, pero no se aprecian restos de signos posteriormente. La segmentación en sí no es clara.

J.55.1 aokolioneertaune. Dado que se conocen los «onomásticos» acabados en -on y en -ir ${ }^{15}$ y que se conoce el sufijo típico -ne (Untermann 1997, 162; Rodríguez Ramos 2005-2009, 99), que además se repite como final de segmento en la otra mitad de esta misma inscripción, la duda está en si segmentar aokolion eertau-ne o aokolioneer tau-ne (entendiéndolo quizá como equivalente a aokolioniir). Actualmente optaría por la segunda posibilidad ${ }^{16}$.

Mesas do Castelinho: -eanitakalte-tao / pe-saru(*)an. La segmentación se basa en el kalte de J.1.1 y en el saru-ne de J.22.1 y J.22.2, quedando pues una comparación con tao o la interesante taope.

Monte Gordo: -eronparena / ŕ ]kentapeano(*)ion. Estaría segmentado por un final formular eron pare na[ŕ] ken. Es interesante comparar la forma tape con Mesas do Castelihno y J.6.2.

Formas con la ta «heth»:

J.10.1 -enseretau\#. Como ya se ha indicado es un final comparable con el de J.54.1.

J.6.2 ] tape[. Lamentablemente es todo cuanto se conoce de la inscripción, pero la comparación con taope y tape es sugerente.

En definitiva, podríamos tener un segmento tau que en ocasiones apareciera como tal y en otras recibiera el conocido sufijo -ne, mientras que las grafías tape y taope podrían estar reflejando un tau-e con sufijo e (la labial sería la sonora $b$ ). Incluso aunque no se aceptara esto, persistiría la comparación tau / tao ${ }^{17}$.

15 De Hoz 1989, 535, ya los presenta como sufijos propios de los términos iniciales que parecen ser antropónimos junto con otros (Cf. también Untermann 1997,161 s y 166 , quien prefiere segmentar -oir más que -ir). El tercer sufijo de los «antropónimos» más importante para De Hoz y Untermann sería ea; que, por mi parte, ya desde 1992 (370 y 375) he preferido segmentar como término autónomo. Cf. Rodríguez Ramos 2005-2009, 96.

16 Como indico en Rodríguez Ramos (2000b) la estadística de los usos sugiere con un amplio porcentaje que la mayoría de los casos de geminación vocálica se asocia a finales de palabra cuando terminan en la propia vocal o en $\mathbf{r}$ (siempre y cuando no les preceda un pseudo-silabograma), pudiendo tratarse de un recurso ortográfico de algunas escuelas de lapicidas.

17 La evaluación de si hay una alternancia $\mathbf{p}$ / u / o (es decir b/w/v) antevocálica es difícil, pues depende de las interpretaciones que se hagan de los segmentos. En 3.4 veremos una posible comparación de segmentos iopa, iupa con ionpa y quizá también con ioua[. Es sugerente el segmento leoi-ne (J.10.1) incluso para supo- 
Finalmente menciono una posibilidad interesante pero muy especulativa. Se trata de un segmento de la inscripción de S. Martinho. Separando de forma arbitraria un inicio tenemos: -kualakiMuŕ⿴囗十a-naŕkepa. En este segmento podemos hacer una separación ante el elemento formular naŕke. El primer signo no transcrito es uno que siguiendo a Correa y a Untermann se ha propuesto leer como $\mathbf{m}$, el segundo es un «heth» ante a y, por tanto, verosímilmente $\mathbf{t}$.

En la lectura resultante lo primero que llama la atención es la comparación con el topónimo Lacimurga / Lacimurgi, sito no lejos de Medellín y por tanto cerca de la zona de uso de las estelas y bien conocido por las fuentes e inscripciones latinas (Sáez Fernández 1990; Aguilar Sáenz et alii 1992-1993; Almagro-Gorbea 2008, 96).

Aunque en esta inscripción no se documenta ka, dado que las formas de "heth» ante a coinciden en otras inscripciones con la forma conocida de ka, es extremadamente improbable que se lea **lakimuŕḱa. Pero si tenemos en cuenta que en la serie de topónimos tartesios tenemos un Lacippo, entre otros, y una larga serie de topónimos en -urgi, que incluye un Murgi (resumen en el mismo Almagro-Gorbea 2008, 94) no cuesta mucho identificar un elemento toponímico «laki». Si seguimos esta obviedad puede ser relevante comparar la posible lectura lakimuŕta con la ceca romana de MURTIL, (Myrtilis / Mértola), también en el Guadiana y de donde procede la inscripción J.28.1. La comparación es sin duda muy insegura, pero es interesante por plantear la posibilidad tanto de relacionar las inscripciones con su entorno lingüístico, como por poder dar indicios sobre el valor fonético de tres signos ${ }^{18}$.

\subsection{Sobre los signos de pu y $\boldsymbol{k u}$}

En lo que concierne al problema de la identificación de los signos de pu y de $\mathbf{k u}$, es decir de las lecturas de los grupos de signos 收 y $4 \underset{W}{ }$, en este o en el orden contrario, mi solución ha favorecido la relación formal entre los signos para vocales posteriores; mientras que el estándar de Correa y Untermann es al revés. De esta manera, al igual que para to y tu las formas son derivadas (to $\Delta$ es una variante formal de tu $\Delta$ que es «daleth»), el signo $\bigotimes$ sería un derivado de ko $\bowtie$, mientras que las formas de «heth» se usarían para po y pu (por más que para po fuese mucho más frecuente la forma simplificada como rectángulo $\square$ ). Esta propuesta era coherente con un modelo más am-

ner que o muestre una semiconsonante y tenemos un inicio oar[ (J.22.2) en una posición donde esperaríamos pare. Un problema relacionado puede ser la aparente alternancia de pi con ii (naŕkenii / naŕkenpi; o en finales de «onomásticos» -poiir / popir, pero también existe -ponir) que podría interpretarse como un reflejo $\mathrm{de} / \mathrm{w} /$, entre otras posibilidades. Aboga en contra el que el repetido uarpan no aparece como ${ }^{* *}$ parpan.

18 Incluyo entre estos tres el signo $\mathbf{r}$ porque su valor en «tartesio" no es totalmente claro. Su origen formal es probablemente «zayin» (Rodríguez Ramos 1992, 337 y 376s; 2002b: 205s) por lo que pudiera tener un valor sibilante, pero su signo derivado en íbero es la segunda «r» (quizás una vibrante retrofleja). En el monumental tartesio tenemos las curiosas variantes formulares naŕrkeni (J.1.2) y naŕrke* (J.23.1), mientras que J.16.3 podríamos tener itiaríeran[, lo que parece confirmar su relación con «r», pero también sugiere un sonido de as- pecto compuesto. Puede recordarse la vibrante postalveolar fricativa u oclusiva sonora vibrante alveolar intermitentemente fricativa (Laver 1994, 264) que aparece, por ejemplo, en checo, que suele ser percibida como una especie de «rs»; mientras que un fenómeno epigráfico similar lo tenemos en osco en el signo vibrante que en inscripciones latinas aparece como RS. Es interesante el paralelo con el sumerio, donde el signo ř en una fase antigua tiene carácter asibilado (como indican préstamos mutuos con el acadio, donde se señala con el mismo signo que para la $\mathbf{z}$ /ts/ sumeria) para luego fundirse en neo-sumerio con $r$ en los dialectos centrales y $d$ en otros. Jagersma $(2000,86 s)$ indica que originariamente sería una africada aspirada sorda dental o alveolar $\left[\mathrm{ts}^{\mathrm{h}}\right]$. El paralelo sumerio es pertinente en tanto que el «zayin» fenicio habría sido precisamente una sibilante africada de tipo /dz/ (Krahmalkov 2001, 21s) mostrando, pues, una posible evolución de «zayin» a una rótica. 
plio sobre la formación del sistema (Rodríguez Ramos 2000, 33s), pero carecía de un paralelo textual claro. Esto es precisamente lo que parece aportar la inscripción de Mesas de Castelinho.

Veamos una transliteración completa de la inscripción separando solo las segmentaciones más evidentes:

\section{tilepurpuarkasta $\left[^{*}\right]$ uteban \\ tilepoiir ero pare naŕk $\mathrm{e}^{\mathrm{e}}$ 3-4] lakiuu / \\ lii $\left[{ }^{*}\right]$ eianiitaeanirakaltetao / pesaru $(*)^{19}$ an}

Hemos indicado que uno de los finales más típicos de los elementos variables iniciales (que en principio serían onomásticos) son los finales en -on y en -ir. También es normal que estos elementos iniciales parezcan acabar en r. De esta manera parece verosímil que el primer elemento, presunto onomástico, sea tilepur ${ }^{20}$. Pero resulta que tras la segunda esquina de la inscripción es como si tuviéramos el inicio de una «frase» «normal» con la fórmula clásica. Encabezando esta oración en posición de onomástico tenemos un tilepoiir con un final típico de estos elementos ${ }^{21}$. Puede sospecharse que tenemos un mismo nombre en dos casos morfológicos.

Naturalmente no es una prueba incontrovertible. Aunque de hecho los paralelos textuales de poiir no lo facilitan, podría proponerse que nos encontrásemos ante dos antropónimos emparentados con un primer elemento común ${ }^{22}$. Pero incluso esta interpretación solo sería neutral (no dando ventaja a ninguna alternativa) y la cuestión es que mientras para buscar alternancias con po que defiendan un valor pu al signo tenemos buenas opciones, no parecen encontrarse argumentos equivalentes en sentido contrario.

\subsection{La problemática del signo $M$}

Dentro de mi esquema, en un intento de simplificar las aparentes irregularidades del signario y ver si se podía encontrar una explicación sencilla con solo tres series de silabogramas de oclusiva como en las demás escrituras paleohispánicas, hice una propuesta para cubrir el vacío que dejaba la escasa presencia del signo $\mathbb{W}$. La forma $\boldsymbol{M}$ que también se documenta solo ante $\mathbf{u}$ y que guarda una cierta semejanza sería una variante simplificada, siendo ambos alógrafos.

Pero esta feliz idea se ha encontrado con el testimonio de la inscripción de S. Martinho, donde aparecen ambos signos a la vez y ante u. Esto anula la hipótesis y es menester revisar el modelo de signos consonánticos ligados a vocales en la escritura redundante monumental tartesia. Esto nos lleva al apartado cuarto.

19 A propósito de este signo extraño que no transcribo, que es un arco grande con varios apéndices y que presenta un tamaño significativamente mayor que las otras letras, mi impresión es que podríamos estar ante una notación numeral. La misma sugerencia valdría para el signo extraño de la penúltima línea de J.10.1 inn. ¿Tal vez la representación gráfica de un instrumento de cuenta y numeración previo a la escritura?

20 Ya Guerra 2009 segmenta aquí lo que considera un antropónimo que lee tilekur.
21 Cotéjese por ejemplo con J.1.5 śutuir ea par[e n] aŕkenti; J.7.1 aśtapopir naŕkenai, J.11.3 soloir uarpan; o el más cercano J.22.1 uarpoiir sarune sin ser exhaustivos.

22 Para este planteamiento podrían aducirse las inscripciones J.1.1, J.7.1 y, con grandes problemas, J.16.4. El caso más claro sería J.7.1, pues el lokonane de J.1.1 (a comparar con su inicio lokoponiir) por su terminación en -ne parece un tipo de palabra diferente a los antropónimos. 


\subsection{Revisitando el problema de «m»: los posibles dígrafos -np-y los signos «muoides»}

Desde que Correa retomase el camino emprendido tan meritoriamente por Schmoll sobre el desciframiento de la escritura tartesia, ha venido planteando la posibilidad de que existiera una notación para la oclusiva nasal labial $/ \mathrm{m} /$. Como es habitual en él, su planteamiento es lógico y argumentado: además de que aparecen signos similares a formas fenicias de «mem» y griegas de «mu», un argumento clave es que en los topónimos de la zona suroeste y tartesia se documenta la existencia de M (así Munda, Munigua, Myrtilis, Maenuba, Detumo o Carmo) (Correa 1992, 93 y 95). Puede añadirse a eso el que la inmensa mayoría de las lenguas del mundo tienen un fonema $/ \mathrm{m} / 23$.

A esta cuestión presté especial atención en mi tesis de licenciatura, sobre todo al hecho de si a las tres series de pseudo-silabogramas conocidas $(\mathbf{p}, \mathbf{t}$ y $\mathbf{k})$ se podía añadir una cuarta serie en $\mathbf{m}$. El resultado era que los datos no permitían reconstruir una cuarta serie completa para las cinco vocales, sino solo para a y para $\mathbf{u}^{24}$. Los otros posibles signos candidatos eran demasiado poco frecuentes y formalmente solo ante e podía intentar buscarse una conexión formal con «m».

Así las cosas, para la primera el signo sobrante sería o bien ₹ (forma tipo letra fenicia «mem») o más probablemente $\mathbf{s}$ (tipo letra fenicia «he»), mientras que para $\mathbf{u}$ el signo sobrante sería $\boldsymbol{M}$. Aunque se incluían dos formas muoides, dada su frecuencia de uso, resultaba preferible identificar \{ con pa en vez de darle un valor ma o similar. Por ello el signo sobrante no sería muoide.

Esta conclusión proponía un número total de signos para el sistema que coincidía con el número de signos del alfabeto de Espanca (es decir, su total de «letras» diferentes); cuya cantidad sería igual a sumar las tres series previstas de pseudo-silabogramas, más los signos vocálicos y consonánticos sencillos ya conocidos, más uno. Faltarían en este alfabeto un mínimo de cuatro signos para poder considerar que era un signario con cuatro series de pseudosilabogramas ${ }^{25}$. En mi solución, el «más uno» del alfabeto de Espanca, sería «he» con un valor de $\mathbf{h}$ que se presentaría solo ante a por condicionantes fonéticos (Rodríguez Ramos 2002b, 208, nota 28). En la solución de Untermann el adicional sería el signo ante $\mathbf{u}$ que sería $/ \mathrm{m} /$ presentándose ante $/ \mathrm{u} /$ también por condicionantes fonéticos.

El problema es que hay diversas cuestiones a considerar. La primera es que efectivamente la lengua en la que están escritas las estelas tuviese un fonema $/ \mathrm{m} /$, algo probable pero no obligatorio. La segunda es que la escritura pudo ser defectiva: es decir, que no tuviese signos para todos sus fonemas (algo que es mucho más normal de lo que se suele creer), de manera que es posible que sí tuviese $/ \mathrm{m} /$ a nivel fonemático, pero sin reflejo gráfico. Una tercera cuestión sería que, como propone De Hoz, la escritura de las estelas no fuese la tartesia originaria, de modo que hubiese habido un paso intermedio y dos adaptaciones. Como de costumbre nos movemos con una incómoda cantidad de incertezas y variables.

Para el caso de $/ \mathrm{m} /$, extrańa que, de existir en la lengua adaptadora, no fuese un signo libre como $\mathbf{n}$ o $\mathbf{1}$. Una explicación plausible es que la causa fuera que, como es habitual en muchas lenguas, en posición final solo pueda existir o $/ \mathrm{n} / \mathrm{o} / \mathrm{m} /$ (ejemplo evidente de esta neutralización:

23 Sobre un amplio muestreo de más de 300 lenguas se aprecia que con un porcentaje casi idéntico tanto en las que tienen muchos fonemas como aquellas de pocos fonemas un $93 \pm 1 \%$ de lenguas poseen el fonema $/ \mathrm{m} /$ (Laver 1994, 573).

24 De manera similar en los intentos de Correa 1992, donde con dudas apuntaba unos posibles signos ma y mu.
25 A propósito de Espanca y el problema de la ausencia de «resh» en la primera serie (para los signos finales sí puede proponerse que aparezca), mientras que haya un extraño signo en forma de arco en su probable lugar, tal vez la explicación más sencilla fuese que este signo es un derivado de ŕ y que se hubiese producido una confusión e intercambio de posiciones entre este y $\mathbf{r}$. 
compárense las desinencias de griego clásico y latín), de modo que $/ \mathrm{m} /$ solo existiera ante vocal. Esto y las fuertes limitaciones de posibles oclusivas iniciales descubiertas por Correa (2002) en el estudio de los topónimos de la Bética pudieran ser los motivos de la extraña adaptación del alefato fenicio a un alfabeto con signos de oclusiva, uno para usar delante de cada vocal, pero sin diferenciar entre sordas y sonoras ${ }^{26}$. Para mí este planteamiento es el más interesante.

Vale la pena explicar cómo el análisis toponímico de Correa, aunque de apariencia sencilla, permite dar una perspectiva nueva a la comprensión de la primera escritura paleohispánica. Si, como indica con contundente evidencia, en posición inicial de los topónimos solo podía aparecer de cada punto de articulación de las oclusivas orales una de ellas (la sonora de la labial; la sorda de la dental y la velar) es verosímil que al pronunciar los valores y nombres de las letras del alefato fenicio se produjera esa misma neutralización (de modo que no tendríamos que contar con "gimmel» sino * «kimmel» o similar, ni con «dalet» sino * «talet» o similar ${ }^{27}$ ). El que solo haya inicios en B- pero no en $\mathrm{P}$-, al ser sorprendente que en este caso prime la sonora, podría indicar que las escasas formas con -P- que se documentan en los topónimos sean en realidad secundarias (en el frecuente -IPPOpodríamos estar ante una /b/geminada). En un escenario tal, una eventual inexistencia fonemática de /p/ podría haber hecho que $/ \mathrm{m} /$ se entendiera como el par natural de /b/; de manera que si ka sirviera para $/ \mathrm{ka} / \mathrm{y} / \mathrm{ga} / \mathrm{y}$ ta para $/ \mathrm{ta} / \mathrm{y} / \mathrm{da} /$, pa se hubiese podido entender como para $/ \mathrm{ba} / \mathrm{y} / \mathrm{ma} /$.

Con esta hipótesis no solo razonaríamos mejor la formación del alfabeto tartesio y sus peculiaridades, sino que sería sencillo explicar que efectivamente $/ \mathrm{m} /$ existiera en la lengua tartesia, pero que se indicara mediante los signos de $\mathbf{p}$.

En esta sección voy a hacer una reevaluación de la problemática de la notación (o no) de /m/ y a exponer una propuesta provisional de solución tal como me parece más viable en la actualidad. En concreto voy a centrarme en dos problemáticas que podrían estar relacionadas: la de un posible uso digráfico de las secuencias -np- (donde por $\mathbf{p}$ entenderíamos sus cinco variantes) y la de los signos muoides.

26 El problema de la adaptación de un alefato a un pseudo-silabario (de hecho un alfabeto) ha sido desarrollado y tratado en múltiples artículos por De Hoz con muchas aportaciones interesantes (su síntesis más reciente en De Hoz 2010, 488-525). Para mi revisión de la cuestión, cf. Rodríguez Ramos 2002b y 2004, 41-69. La datación paleográfica siempre ha sido clara, por más que su desdeño por parte de los arqueólogos como cosa «filológica» influyera en De Hoz para rebajar las dataciones pese a su correcto planteamiento. Pero la paleografía es un elemento morfológico de rasgos múltiples objetivables con coherencia interna y, por tanto, tan válido o más que otras morfologías al uso. Los prejuicios contra una evidencia sin dejar que los datos determinen la información que puedan dar son un claro error de concepto que elude el análisis concreto. Ha tenido que ser el respetado $\mathrm{C} 14$ el que corrija las cronologías arqueológicas antes tan definitivas (véase el cambio radical entre Aubet 1987, 189s y su segunda edición 1994, 323) y reivindique la datación paleográfica. Desde un principio (Rodríguez Ramos 1992, 329: «en los alrededores del 800 a.C., tal vez con un arco de 825-775 a.C.») he intentado seguir la crono-paleografía objetivamente. Pero debo reconocer que algo me debí dejar influir, pues tras revisar los datos creo que hay que elevar algo la datación. La datación más probable estará en el tercer cuarto o incluso mejor en el segundo tercio del s. Ix. El último cuarto es técnicamente posible pero ya requiere algunas suposiciones incómodas.

27 A propósito, podría plantearse un uso puramente acrofónico de la lengua fenicia para explicar las formas de signos adicionales. Así el signo te 月 es básicamente la hoja de una "puerta» como el significado de «daleth» lo que podría justificar su uso para la dental faltante, e igualmente po $\mathbf{D}$ sería la representación de una casa «bayt» tomando un valor de labial. Esta explicación, que supondría una especie de recreación acrofónica de formas más ideográficas pre-fenicias, dista mucho de ser satisfactoria, pero abre una posibilidad interesante. Por otra parte, la atribución que hace Valerio $(2008,124)$ de un origen de po en la "pe» fenicia no parece precisamente evidente.

28 De hecho, va en el sentido de un comentario del propio Correa en el tribunal de mi tesis sobre que, habiendo descartado yo la posibilidad de que el signo $\boldsymbol{M}$ fuese una adaptación de formas tardías de la «mem» fenicia o que proviniese del griego, subsistía la posibilidad de que fuese simplemente un signo $\mathbf{n}$ con un diacrítico. 
La cuestión de los muoides es en la práctica una revisión actualizada de las viejas propuestas de Correa $^{28}$. El análisis de los posibles dígrafos es una novedad ${ }^{29}$ favorecida por los nuevos hallazgos. El fenómeno ha de tener una explicación: o bien es un sistema digráfico ${ }^{30}$ (en cuyo caso parecería que fuese para notar $/ \mathrm{m} /$, pero podría tener algún otro uso) o bien hay un sorprendente fenómeno en la morfología de la fórmula por solucionar, existiendo un sufijo - $n$ de amplísimo uso aparentemente demasiado ubicuo. Una tercera opción, la de un mero problema fonético, aunque técnicamente no es imposible, presenta dificultades notables.

Empecemos pues por documentar lo que parecen ser unas alternancias entre -p- y -np-. Resumamos los datos fundamentales:

\section{Comparación de segmentaciones:}

Forma normal: fórmula ea pare / ero pare / e pare ${ }^{31}$

]naŕkeniiraśen-pare (J.7.10) (segmentación poco clara)

]onlinpoir-ean-pa $[$ (J.11.2)

] earon paren naŕkenii (J.11.4) (problemática: conocida por dibujo antiguo)

]ukeśa-en-pare-naŕken[ (J.27.1) (problemática: conocida por dibujo antiguo)

naŕke-pa / ean-para (S. Martinho)

arkar-eron-pare-na / ́́ ] ken (Monte Gordo)

\section{Forma normal uarpan \\ uarn/pan e[?] par[e]n naŕken[ (J.20.1) $)^{32}$}

29 En Koch 2011, 148, entre las diversas grafías en donde propone la presencia de una $/ \mathrm{m} /$ celta incluye también $\mathbf{n}$ seguido de silabograma labial, pero sus propuestas no pueden considerarse aquí porque no parten de criterios de la escritura, sino para encajar sus etimologías. En este caso parece que la $/ \mathrm{m} /$ deriva de la sugerencia de Correa sobre uarpan, aunque finalmente, manteniendo la interpretación fonética haya decidido dejar de lado la verosimilitud semántica (que era la base del razonamiento de Correa que justificaba una interpretación celta), para proponer un significado «místico». De esa "metodología» deriva la tendencia a que las grafías tengan múltiples valores y los fonemas múltiples expresiones gráficas, según necesite la comparación. Koch no ve ningún problema, no solo en "encontrar» emes reflejadas con procedimientos gráficos diferentes en una misma inscripción, sino incluso en una misma "palabra». Sobre las propuestas de Koch, resulta muy certera la evaluación de Mikhailova $(2010,145)$ de que recuerda las resoluciones de problemas cuyo resultado es conocido de antemano (es decir, que se trata de saber cómo se llega al resultado). De hecho, posteriormente Koch ha ido cambiando sus reconstrucciones para llegar siempre a la misma conclusión. Koch deduce de su conclusión, no induce de los datos. La justificación de las transcripciones, de la segmentación, el análisis interno, la estadística o la semántica de los paralelos epigráficos, etc. son detalles sin importancia que se subordinan a sus etimologías, por más que estas sí cambien constantemente y no inspiren precisamente confianza. El sesgo expositivo, el que problemas obvios se los tengan que indicar los demás, la minimización o no mención de datos y argumentos publicados que puedan dar problemas a sus teorías, así como la, de hecho, escasa o nula novedad de muchas de sus propuestas (incluida la famosa de te-ro-bare a la irlandesa medieval) tampoco son la mejor carta de presentación.

30 Es bien conocido el procedimiento de usar dos letras (a veces incluso más) para notar un sonido para el que falta en el signario que se usa. Así los grupos «ch» o «ll» en castellano; "tx" en vasco; "sh" o incluso «ea» en inglés; «au» o «eau» en francés; etc.

${ }_{31}$ P. ej. ]nośta e pare naŕken (J.14.1) y oó́oir e p[are naŕ] kenii (J.19.1).

32 Por paralelos se esperaría que el signo destruido tras la e fuera una a, pero en la fotografía de los MLH (Untermann 1997) se aprecia un trazo que no sigue lo que se esperaría de a pero que coincidiría con la parte última superior de una $\mathbf{i}$ o una $\mathbf{n}$. De esta manera es planteable que tengamos precisamente enpare. 
Forma normal: poiir. Así uarpoiir saru-ne (J.22.1), tilepoiir ero pare (Mesas do Castelinho). Posible alternancia: ]onlinpoir ean pạ $[$ (J.11.2)

Caso problemático: Forma normal: iopa / iupa Así: ...untur ea iupa (J.7.8); aarpuior-ioua[ (J.7.6); ] anpatiaiopa[̨rre na?] ŕke (J.16.2). Posible alternancia: iru-paruaionpa[ (J.7.9)

Posibles contraargumentos:

1) alternancia ] saru-ne ea oar[ en J.22.2, donde tras ea esperaríamos encontrar pare (p. ej. J.22.1: uarpoiir saru-ne ea pare naŕkenii); 2) encontramos una $\mathbf{n}$ adicional en posición que no tiene la misma explicación en una o dos inscripciones del grupo de ejemplos en la secuencia paren naŕke: ] earon paren naŕkenii (J.11.4, aunque de lectura insegura al ser sobre un dibujo) y uarn/ pan e[?] par[e]n naŕken[ (J.20.1).

Cuestiones que pueden afectar a la interpretación:

En la estela de S. Martinho además del sospechoso ean-para encontramos también el uso del signo $\boldsymbol{M}$. En J.1.1 si efectivamente hemos de identificar un signo $\boldsymbol{n}$, entonces es relevante indicar que aparece junto a un pare normal (O१A६).

Hace tiempo que se conoce la extraña forma uarnpan, especialmente interesante porque se supone que el muy frecuente segmento uarpan es una "palabra", de modo no esperamos que haya una variación morfológica interna. Por ello, en principio, o es una alternancia o es un error del lapicida.

Esto último parecía la hipótesis más verosímil, pues, aunque existían algunos casos en los que ante elemento formular pare hay una $\mathbf{n}$ antepuesta, eran discutibles: dos eran de inscripciones conservadas solo por dibujo (11.4 y 27.1), en dos la segmentación era poco clara ( 7.10 y 11.2; aunque en esta última es muy probable) y en una donde la reconstrucción precisamente del signo n, aunque aparente, es incierta (J.20.1). Pero dos nuevas inscripciones han aportado más evidencia.

Los casos de npare no son los únicos en que se encuentra el signo $\mathbf{n}$ ante uno de $\mathbf{p}$, pero no siempre puede hacerse una segmentación clara. Entre los casos que merecen tenerse en cuenta tenemos -poiir / -npoiir y iopa / ionpa.

Como contraste, he intentado extrapolar el análisis a otros posibles dígrafos con las otras dos oclusivas, a fin de ver si sería un fenómeno exclusivo de la oclusiva labial o no. Efectivamente hay casos de nt y nk, pero son muchos menos que los casos de np y no se identifican contextos que permitan evaluarlos como alternancia (como mucho las variables de naŕkenti que evidentemente son parte de una variación más compleja).

De este modo la información actual sugiere que el fenómeno de los dígrafos se limita al grupo np y que requiere una explicación específica para la labial. Sin embargo, es obvio que los datos, si bien son una muestra indiciaria coherente, son pocos y pueden estar distorsionados por la frecuencia de elementos que se repiten en las inscripciones que presentan signos en $\mathbf{p}$ (especialmente en pa). Esto último afecta tanto a la frecuencia de los ejemplos, como a la propia posibilidad de identificar una alternancia. Por ello, aunque el indicio es válido para suponer que el fenómeno se limita a las labiales, es difícil valorar exactamente su significancia y debe considerarse provisional.

Otro de los problemas a los que nos reduce la escasa documentación es que las evidencias cuentan más cuanto mayor es el número de sus ocurrencias. No podemos descartar la presencia de segmentos similares pero diferentes: de variaciones morfológicas en fórmulas que nos parezcan iguales, de variaciones dialectales o de simples erratas del lapicida. Cuando nos encontramos con un 
dato basado en un caso aislado, es muy difícil conseguir una certeza y una precisión en el análisis. Por otra parte, si, como supongo, nos encontramos ante una innovación en un intento de mejorar la escritura, entonces ni nos vamos a encontrar un testimonio consistente homogéneo, ni podemos descartar desarrollos irregulares. El panorama, pues, no es alentador.

Hechas estas necesarias advertencias, pasamos a comentar las posibles contra-evidencias. La existencia de inscripciones sin el dígrafo no supone ningún problema, pues el dígrafo debiera de ser una innovación para mejorar la notación de la lengua.

La posible alternancia de J.22.2 es interesante porque plantea que otra forma de escribir pare fuese oare. Esto apuntaría a que la pronunciación fuese "ware» / "vare», es decir, más similar a «bare» que a «mare»; puesto que, aunque las alternancias fonéticas $m / w$ no son inusitadas, en este caso concreto no aprecio indicios a favor. El problema de este ejemplo es tanto que la reconstrucción de que aquí tengamos pare es verosímil pero incierta (si apareciera el fragmento que falta y en realidad tuviésemos ${ }^{* *}$ oarpan no nos sorprendería demasiado), como que resulta llamativo que, entre tantos casos de pare bien y claramente testimoniados que tenemos, ninguno más presente la alternancia. Dato interesante, pues, pero poco definitorio.

El segundo problema es la inscripción J.20.1 y el segmento uarn/pan e[?] par[e]n naŕken[. La nueva evidencia apunta a que uarnpan no es una errata, sino que podríamos tener un fenómeno de digrafía. Como el signo que va tras la primera e, muy dañado, deja algunos restos que encajarían con la parte superior delantera de una $\mathbf{n}$, resulta que podría incluso proponerse que tuviéramos también un caso de npare. Pero eso nos deja con la doble $\mathbf{n}$ de par[e]n naŕke y el problema de qué explicación darle. Este caso de doble n, si bien es un ejemplo aislado, apuntaría a una alternancia morfológica con concordancia más que a un dígrafo.

La tercera cuestión es la coexistencia de un aparente caso de dígrafo con un uso del signo $M$. Si este signo fuese una forma de notar $\mathbf{m}$, como es legítimo plantearse y Untermann presenta como seguro, entonces cabría plantearse qué sentido tiene notar a la vez este fonema también mediante dígrafo. Aparte de la posibilidad, poco sistemática pero técnicamente posible, de suponer que el dígrafo fuese un fenómeno que se especializara con pa (de hecho de las alternancias propuestas casi todas son con pa y solo una, menos clara, con po; pero ya hemos indicado que precisamente las secuencias con pa son especialmente frecuentes), sería consecuente plantearse si esta digrafía no notaría otra cosa (como por ejemplo la sonoridad). Problema similar plantea la posible coexistencia de $\boldsymbol{n}$ con pare en J.1.1 si esto alterna con npare; aunque aquí el dato es incierto por la problemática de este signo del que no se puede asegurar ni su existencia como tal.

\subsubsection{Los signos muoides}

En el planteamiento de los signos que por motivos formales pueden relacionarse con posibles valores de $\mathbf{m}$ (o de una segunda nasal) hay dos aspectos. De un lado tenemos una serie de signos de valor no claro cuyo testimonio es escaso salvo para $\mathbf{M}$. De otro tenemos la cuestión del signo «sobrante» ante a, dado que uno recuerda a «mem» y otro a «he», habiendo de ser uno de ellos el valor pa. Aunque una identificación de $\mathbf{m}$ apuntaría a la forma «mem» y, de hecho, la forma "he» es en íbero meridional pe (es decir, concordante con un valor pa en tartesio) ${ }^{33}$, en principio este «mem» es pa.

\footnotetext{
33 Concuerda también el que la forma del pa íbero meridional parece una evolución del pe tartesio.
} 
La consideración contraria tendría que explicar tanto que la secuencia «ma» sea mucho más frecuente que la secuencia "pa» (lo que de por sí no es fácil de explicar), como además el que esa eventual gran frecuencia de "ma» contrasta con la, en el mejor de los casos, ínfima de los posibles «me», «mi» y "mo», así como poca de "mu». Además, al ser un signo fenicio originario, si se le hubiese dado un valor de $\mathbf{m}$ se esperaría que, o bien fuese un signo que apareciera con normalidad ante todas las vocales ${ }^{34}$, o que los eventuales signos pseudo-silábicos (tipo me, mi, mo y mu) derivaran formalmente de la forma «mem», no de n. Por todo esto no puedo incluir $\}$ en la lista de muoides.

Veamos los posibles muoides y signos no aclarados que pudieran relacionarse:

-Ante a:

n: J.1.1; J.1.4 (testimonio problemático).

-Ante e:

ఛ: J.15.1;

-Ante i:

$\Psi: \mathrm{J} .12 .4$

Y: J.28.1 y Monte Gordo;

ง: J.7.5

-Ante $\mathbf{u}:$

Y: J.7.8, J.12.1, J.16.2 y S. Martinho;

$\uparrow$ (o similar, solo se conserva la parte superior) Mesas do Castelinho.

Se comprueba que hay tres signos cuyas formas podrían explicarse como creadas a partir de $\mathbf{n}$ (y), pero que ni hay ninguna forma candidata para signo ante $\mathbf{o}$ ni ninguna de las formas ante $\mathbf{i}$ permite una relación con $\mathbf{n}$.

Un problema adicional lo constituye la forma ante a, pues su existencia es dudable. Está sobre la piedra bien marcada en J.1.1, mientras que menos clara en J.1.4. Pero en esta, el que el trazo largo final rompa su inclinación no encaja con una forma ka pareciendo como un signo $\mathbf{n}$ muy elevado al que se la ha añadido una base bajo el ángulo. También podría considerarse que este cambio de inclinación se debiera a un error del lapicida con corrección. Untermann considera ambas formas

34 Valerio (2008) llega a afirmar que es m (como signo libre) por su origen en «mem» argumentando que también se encuentra ante e (de hecho solo dos casos, como vimos en 5.1, y uno de ellos como variante del formular pare). Valerio no aprecia la desproporción de uso que deja de a sobre e o sobre las otras vocales (en general presta poca atención a las cuestiones de frecuencia, con propuestas que producen extrañas irregularidades; p. ej. sobre te). Como contraste podríamos preguntar a qué conclusión debiéramos llegar si tenemos en cuenta que el rectángulo po formalmente se encuentra también ante a y e. Cabe tener en cuenta que esta no es su especialidad de trabajo (p. ej. cree que el corpus más moderno es el de Correia), siendo normal que no esté familiarizado con su problemática.
35 Posiblemente esta forma se encuentra en J.18.3, como entiende Untermann, pero no puede precisarse el signo que le sigue, por más que lo poco que queda sería compatible con i. La forma se encuentra también en el signario de Espanca como un signo más, pero este signario presenta diferencias importantes respecto a la escritura de las estelas, pareciendo corresponder a una variante muy evolucionada. Una variante tumbada se encuentra en un fragmento de línea problemático de J.11.5. Son cuatro signos que por la dirección de $\mathbf{i}$ debieran ser finales y presenta dos formas extrañas y una secuencia «final»-iki $\mathbf{i}$. Tal vez la hipótesis más sencilla fuera considerar que tenemos una $\mathbf{i}$ invertida (la inversión ocasional en la dirección de los signos tiene paralelos, como en J.54.1) y entonces tal vez el tercer signo fuese una variante algo mal trazada, teniendo un inicio más normal kir-. 
simplemente como ka, indicando que en J.1.1 el trazo superior sería un daño de la piedra, aunque su aserto inicial acaba siendo dubitativo ${ }^{36}$. Por otra parte, es llamativo que estos dos posibles signos muoides ante a procedan precisamente del mismo yacimiento, como si fuesen una invención local.

Si hubiésemos de darles un valor a ambos signos usando la comparación textual, lo más evidente sería considerar que son $\mathbf{n}$, ya que en J.1.1 tendríamos (subrayando el signo en cuestión) un naŕr [k] en en J.1.1 y en J.1.4 un naŕr. Desde ese punto de vista tendríamos que entender que son errores y correcciones por $\mathbf{n}$. Sin embargo, la $\mathbf{k}^{\mathbf{e}}$ de la primera no es más que una reconstrucción plausible y en J.1.4 es muy difícil que los restos del signo tras la ruptura sean ke; así que esta comparación es muy dudosa. La otra posibilidad que aportan los paralelos sugeriría que en J.1.1 tuviésemos un conocido segmento laki, pero a nivel gráfico es inverosímil.

De esta manera hemos de tener en cuenta la posibilidad de que existiese un muoide ante a, pero que no puede considerarse un dato seguro y que, de existir, parece tener un uso tan local que parece dudoso utilizarlo como muestra de un sistema común ${ }^{37}$.

Ante e sí tenemos un caso claro: $\boldsymbol{\uparrow}$. Proviene de una inscripción de factura un tanto descuidada, pero el signo es bastante claro. La única alternativa formal que se me ocurre es que fuese una variante de ́́r, pero no parece especialmente verosímil. En su momento $(1992,265)$ también barajé la alternativa de que fuese una transformación de $\{$ (con lo que sería un pe) pero es una hipótesis harto complicada. Tampoco aprecio paralelos textuales. El signo puede entenderse evidentemente como una doble $\mathbf{n}$ como origen morfológico sin que eso deba de entenderse necesariamente como un nexo, puesto que no parece ser un fenómeno habitual en las estelas. Hay que tener en cuenta que, en la inscripción donde aparece, el lapicida no solo ha dejado sin terminar algunos signos, sino que da la impresión de que se ha olvidado de trazar otros por completo (si, como parece verosímil, identificamos el final como la fórmula típica). Ello dificultaría la localización de segmentos paralelos.

Ante u tenemos el testimonio más claro. El signo más frecuente puede entenderse como una $\mathbf{n}$ a la que se ha añadido una tilde, como sugiere Correa, y permite un estudio más coherente.

Los segmentos que presenta (con una segmentación del conjunto no estricta) son: - $\mathbf{e}^{\text {Mun- }}$ tur- (J.7.8); -naŕkenti-Mu-pa-tero-pare- (J.12.1); oMuŕi[ (J.16.2) y -lakiMứt́n-naŕke- (S. Martinho). Si consideramos asimilable el signo en forma de $\mathbf{n}$ geminada ańadiríamos -kasta $\uparrow \mathbf{u t e p a n -}$ No presentan paralelos fiables, aunque quizás merezca mención su comparación con formas de pu (punpane en J.19.1 y 26.1; epuŕ[ en J.4.1).

Dejo para el final la sección de las formas con i porque en realidad no creo que sean relacionables con los muoides; tanto por su forma, como porque parece que pueden entenderse perfectamente como variantes de $\mathbf{p i}^{38}$.

Veamos primero las formas del pi normal: ]akinpaipirolata (J.3.1); aśtapopir (J.7.1); naŕkenpi (J.19.2). Es evidente que en los dos últimos casos sería tentador considerarlo equivalente

\footnotetext{
36 Untermann 1997, 208, empieza indicando que el trazo sobrante es accidental («der Aufstrich links oben ist wohl zufällige Verletzung»), pero luego cree posibles otras explicaciones, como la de Correa de que fuese un nexo -nka-. Opino que el trazo adicional está demasiado bien situado para ser accidental y que la alternativa a considerarlo un signo diferente sería que fuese un signo corregido.
}

\footnotetext{
37 Obsérvese además que mi hipótesis inicial (1992, 272s y 338) de que fuese un signo ka con un apéndice para darle el valor de $\mathbf{h}$ y que sería un alógrafo regional de $\boldsymbol{\Xi}$ es otra posibilidad factible.

38 La discusión sobre la lectura de este signo como pi en Rodríguez Ramos 2000, 34ss.; la relación de las otras formas con este valor, ya en Rodríguez Ramos 2000, 41, S-305 y 42 S-313; y 1992, 265.
} 
a una i pregeminada y comparar con los conocidos poiir y naŕkenii, pero que en J.3.1 quedaría bastante extraño ${ }^{39}$.

Veamos ahora las otras formas:

$\Psi: \quad \#$ saloi $\Psi[] \mathbf{p}^{\mathrm{a} e p a l a k i n} \Psi \mathbf{i}(J .12 .4)$

Y: ]norYion[ (J.28.1); tapeanoYion\# (Monte Gordo)

ง: \#uarposi[ (J.7.5)

Los argumentos para sospechar que se trata de variantes de pi no son contundentes, pero sí coherentes: 1) todas las formas presentan similitud con el signo $\uparrow$, las dos primeras son básicamente geminaciones, la tercera se obtiene moviendo uno de los apéndices abajo; 2) explica la mínima frecuencia del signo pi dándole una proporción más razonable (de 3-4 inscripciones pasaríamos a 7-8); 3) presenta una comparación contextual buena (uarpo $\mathrm{Ji}[\mathrm{J} .7 .5$ con aśtapopir de J.7.1). No puede considerarse una solución definitiva, pero sí una hipótesis muy verosímil.

\subsubsection{El problema de los muoides: planteamiento}

De esta forma vemos que podemos proponer sin problemas signos muoides para $\mathbf{u}$ y para $\mathbf{e}$. Pero que: 1) para a solo es hipotizable (y en el mejor de los casos habría de ser interpretado como un fenómeno muy localizado) o que alternativamente habría que replantearse por completo el signo pa; 2) para i es muy forzado tomar signos que admiten mejor su interpretación como pi; y 3) para o no tenemos ni signo candidato.

La explicación que se pueda dar a este fenómeno es muy difícil, puesto que el caso de e es un «hápax» $y$, aunque la forma propone que sea un muoide, podríamos tener simplemente un signo epicórico local. La ausencia de o es quizás explicable por la aparente tendencia ocasional a fundir $\mathbf{o}$ y $\mathbf{u}^{40}$.

En general, puede decirse que el testimonio de la estela de S. Martinho, al invalidar mi propuesta inicial sobre $\mathbf{M}$, deja como mejor hipótesis la de Untermann, de que se trataría de un signo especial de $\mathbf{m}$ que se usa ante $\mathbf{u}$ por motivos fonéticos y que no sería un pseudo-silabograma ${ }^{41}$. Sin embargo, este planteamiento no acaba de ser satisfactorio.

De un lado, la justificación fonética es problemática. Sería un fenómeno sumamente extraño que la $/ \mathrm{m} /$ alterase el timbre de toda vocal que le siguiera. Además de la rareza del proceso, el fonema $/ \mathrm{m} /$ resultaría poco frecuente, mientras que tenemos bien documentadas las secuencias na, ne, ni y no. Extraña también que no se produjera una asimilación semejante de una $\mathbf{n}$ tras $\mathbf{u}$ (la secuencia un está bien documentada) ${ }^{42}$.

Por todo ello parece necesario explicarlo mediante la mucho más normal asimilación regresiva: que fuese / $\mathrm{u}$ / la vocal la que transformase una nasal dental en labial. Lingüísticamente no

39 De hecho, en Rodríguez Ramos 1992, 258 y mapa 7 , planteaba que la forma cuadrada de $\mathbf{i}$, que coexiste con formas normales, por su uso parecería ser una semiconsonántica de uso epicórico, por encontrarse ante otras vocales, inclusive ante $\mathbf{i}$ en la fórmula de naŕkenii.

${ }^{40} \mathrm{La}$ documentación vuelve a no ser contundente, pero el mejor ejemplo es J.1.1 donde con 75 signos nunca tenemos $\mathbf{u}$, pero sí una muy abundante cantidad de o tal como apunta Correa 1992, nota 62. Cf. también De Hoz 1989, 533.
41 Untermann 1997, 143, nota 42. Esto último y el considerar la lectura como segura son las diferencias entre el modelo de Untermann y lo anteriormente planteado por Correa como un posible $\mathbf{m}^{\mathbf{u}}$.

42 Es interesante recordar que sigue sin documentarse la secuencia paralela lu, una de las que observó Correa 1990, 137 que no se daban en las estelas. Podría haber una relación entre ambos fenómenos. 
sería nada extraordinario, pero entonces el problema es que eso técnicamente supondría que no existiera un fonema $/ \mathrm{m} /$ como tal en «tartesio monumental», sino que sería un alófono de /n/: el signo $\boldsymbol{M}$ se limitaría a indicar una pronunciación especial de $\mathbf{n}$, siendo un fenómeno puramente testimonial. Con todo, este carácter secundario de $/ \mathrm{m} /$ podría justificar que no se hubiese usado el «mem» fenicio.

Pero un problema más de fondo es que los testimonios toponímicos de la Bética no apoyan esas restricciones fonéticas, pues tenemos topónimos como Carmo o Maenuba; donde no solo tenemos $/ \mathrm{m} /$ ante otras vocales y como un aparente fonema normal, sino que además atestiguan el grupo / nu/ (no tenemos ${ }^{* *}$ Maemuba). Es cierto que esto no es definitivo, pues podría haber diferencias dialectales, pero hace que el planteamiento resulte sospechoso.

En todo caso sí que existe un detalle que podría resultar un apoyo. En el testimonio de las estelas, de los cinco casos en que se encuentra la secuencia nu, en tres parece haber un límite de palabra entre $\mathbf{n}$ y $\mathbf{u}$ (porque uarpan nos permiten segmentarlo J.3.1, J.9.1, J.20.1); en un cuarto es muy probable (porque se puede proponer un onomástico inicial con su terminación en -on S. Martinho), mientras que el quinto es un caso que, aunque no permite análisis por su estado fragmentario, también es un on (J.4.4). Esta casuística, de posible inexistencia de la secuencia nu, sí concordaría con la idea de Untermann de un condicionante fonético, aunque en este caso como un archifonema de $/ \mathrm{n} /$ (es decir: /nu/ se pronunciaría $/ \mathrm{mu} /$, pero $/ \mathrm{m} /$ solo sería un alófono de $/ \mathrm{n} /$ ). Esta, pues, sería una hipótesis defendible, aunque con ciertas reservas.

Pero por otro lado tenemos el hecho de que aparezca el signo $\boldsymbol{\uparrow}$ además de ante e con forma igual o muy similar ante $\mathbf{u}$. Dado que ambos casos parecen signos especiales creados a partir de $\mathbf{n}$, cabe sospechar que ante $\mathbf{u}$ su valor sea el mismo que el de $\boldsymbol{M}$ y entonces presumiblemente también ante e. Con todas las reservas que impone su carácter de únicos, supone una dificultad a la idea de que el fenómeno se circunscribiera a ante u. ¿Qué explicación podemos dar a estos hechos?

\subsubsection{El problema de los muoides: una propuesta de solución}

La explicación que parece más sencilla es que en un principio la escritura de las estelas careciera de signo para el fonema $/ \mathrm{m} /$. Esto explicaría que el «mem» fenicio se usase para pa, el número de signos del alfabeto de Espanca, el que no se pueda reconstruir ni un signo $\mathbf{m}$ originario ni una serie coherente de pseudo-silabogramas tipo $\mathbf{m}^{\mathbf{v}}$ y el que para el presunto $\mathbf{m}^{\mathbf{u}}$ se hubieran hecho dos recreaciones diferentes, ambas tomando como base el signo $\mathbf{n}$ en vez de una sola. Ya hemos indicado que la ausencia inicial de un signo $\mathbf{m}$ podría justificarse considerando las notables restricciones en las oclusivas iniciales de los topónimos de la Bética descubiertas por Correa y la plausible eventualidad de que en posición final de sílaba solo existiera el archifonema nasal dental.

En esta fase inicial un sonido $/ \mathrm{m} /$ seguramente se hubiese notado con un signo en $\mathbf{p}$. Existen, en efecto, algunas posibles alternancias entre pu y el posible mu, aunque son muy inseguras. A priori no puede descartarse que se hubiese podido notar mediante $\mathbf{n}$, aunque el problema de si existe o no la secuencia nu sin límite de palabra apunta a que no.

Posteriormente se habrían hecho intentos de reforma para mejorar la notación, buscándose soluciones para $/ \mathrm{m} /$. Este planteamiento indicaría que no aparecería en las inscripciones más antiguas, pero podría ser que no todas las regiones hicieran la innovación, ni todas de la misma manera.

Al menos una de las soluciones para este problema habría sido la creación de nuevos signos a partir de la nasal no pseudo-silabogramática $\mathbf{n}$. Así añadirían un apéndice a $\mathbf{n}$ para crear $\mathbf{M}$ y una geminación especular para crear $\uparrow$. Es posible que también creasen un signo añadiéndole un 
apoyo al ángulo de la $\mathbf{n}$ formando $\boldsymbol{n}$, pero su testimonio es discutible y en todo caso habría tenido un uso muy localizado.

La mayor presencia del signo de $\mathbf{m}$ ante u se debería, como apuntaba Untermann, a motivos fonéticos, pero en este caso se trataría de condicionantes de preferencia en vez de exclusividad, lo que es más compatible con el testimonio toponímico y permitiría explicar el uso de $\uparrow$ ante e. Es posible que hubiese algún condicionante fonético que impidiera la existencia de mi.

El hecho de que estos signos correspondiesen a una o varias reformas del signario original sería lo que explicaría que no se hubiese podido reconstruir una cuarta serie de pseudo-silabogramas, puesto que quizás en ninguna variante diagrapto se llegasen a recrear por completo.

Esta explicación tiene diversas ventajas. De un lado, es más coherente con el origen del signo $\mathbf{M}$, puesto que el origen que apunta Untermann desde el alfabeto griego es muy problemático y además deja inexplicado el que no se usara el «mem» fenicio para la función. De otro, es más flexible, al no ser tan restrictivos los contextos donde exisitiese el sonido $/ \mathrm{m} / \mathrm{y}$ encajar mejor con los paralelos toponímicos regionales. Pero no es una solución incontrovertible: la existencia de otras formas similares a n podrían considerarse coincidencias o inexistentes y podría extrapolarse la idea de Untermann, cuando solo se conocía $\boldsymbol{\uparrow}$ en un caso ante e, de que fuese un nexo nn.

A todo esto se añade el que existe otro fenómeno, las alternancias -n- / -np, que sugiere también un intento de notar el sonido $/ \mathrm{m} /$. Dado que ambos fenómenos apuntan a lo mismo, esta coincidencia supondría un apoyo mutuo y por consistencia daría más verosimilitud a la interpretación de los muoides como derivados de $\mathbf{n}$ para intentar notar $\mathbf{m}$.

La creación de un dígrafo para diferenciar un valor fonético es un fenómeno típico. Como casos similares puede mencionarse que en griego moderno existe el grupo $\mu \pi$ para indicar «b» oclusiva (de forma paralela al dígrafo de la $d$ oclusiva), como recurso cuando la «b» simple perdió el carácter oclusivo; o en egipcio jeroglífico tardío se usó una grafía digráfica «nr» en vez de la antigua «r» para diferenciar que esa « $\mathrm{r}$ » en concreto era de las que se pronunciaban /l/ (Loprieno 1995, 31).

Desde ese punto de vista, los dígrafos np podrían ser otra solución para resolver la notación de $/ \mathrm{m} /$ y de esa manera el dúo pare / npare nos indicaría un /mare/. Esta solución es coherente con el que np sea más frecuente que nt o nk y el que solo para este grupo se identifiquen alternancias y, como hemos indicado, con la existencia de signos muoides y con los indicios de existencia de $/ \mathrm{m} /$ en la zona. Por eso el fenómeno merece una especial atención.

Ello no obstante, el encaje de ambos planteamientos (muoides y dígrafos) no está libre de dificultades y cuestiones por resolver que no se resuelven ignorándolas. Así, la coexistencia en S. Martinho de un eanpara con el signo $\mathbf{M}$ crea un problema objetivo. Aunque el segmento no sea totalmente coincidente, la relación de eanpara con ea pare es lo más probable y sería poco metódico descartarla como una mera casualidad. Técnicamente es posible que coexistieran dos métodos de notación de $/ \mathrm{m} /$ (p. ej. innovación del dígrafo sobre un signario que no había creado una m para a), pero cuanto menos es una objeción a tener en cuenta ${ }^{43}$.

Una posibilidad para explicar la eventual co-existencia de dos recursos gráficos para notar la nasal labial sería que la creación de $\$ respondiera al fenómeno concreto de $/ \mathrm{m} / \mathrm{secundaria}$ proveniente de /n/ por la mencionada asimilación regresiva, de modo que se recurriera a él por la fre-

43 De hecho, aunque es una posibilidad demasiado compleja como para aceptarla sin más, sí que dejaría un conjunto más coherente: que se hubiese creado algún signo derivado de n para notar la presunta $/ \mathrm{m} /$, que acabase especializándose sobre todo con $\mathbf{u}$ y que finalmente se com- plementase la notación mediante dígrafos delante de signos para los que no había (o había caído en desuso) un muoide. Naturalmente, una especulación semejante solo podrá plantearse en serio cuando aparezcan muchas más inscripciones y estas sigan apuntando en el mismo sentido. 
cuencia y consistencia del fenómeno; mientras que el dígrafo y la recreación ocasional (o muy minoritaria) de otros muoides respondiera a una nasal labial con otro origen. Esta idea admitiría diversas variantes como fenómenos diacrónicos, o dialectales que afectaran a que la $/ \mathrm{m} /$ tuviese carácter fonemático y/o primario ${ }^{44}$.

Aunque esta es una idea técnicamente posible, sin más datos de apoyo no deja de ser un molesto «ad hoc», por lo que, si al final esto resultare un problema insoluble, una alternativa es que el dígrafo, de efectivamente existir, indicara otro fenómeno.

Lo más sencillo en este caso sería suponer una distinción del rasgo de sonoridad. Esto encajaría con la aparente alternancia pare / oar[, que sugiere la combinatoria en J.22.2 y que sería coherente con una labial sonora oclusiva tipo «b» o una labial sonora fricativa tipo «V». Pero para esto el problema es que los datos actuales desaconsejan proponer un fenómeno equivalente para $\mathbf{t}$ o k. Puede recordarse la distorsión de la muestra o puede incluso decirse que es un apoyo a que lo que tenemos es una fricativa que afectara única o principalmente a la labial, pero semejante disimetría crea a su vez diversos problemas: ¡cómo se explica esa disimetría en el esquema fonológico?; ¿debemos entender que una sibilante es la fricativa de las otras?; ¡si fuese un proceso de betacismo, por qué uarpan no alterna con formas ${ }^{* *}$ parpan?

Finalmente resta la solución alternativa de considerar la posibilidad de que esta aparente digrafía fuese en realidad un fenómeno de alternancia puramente morfológica gramatical hasta ahora desconocida o que era frecuente la caída en la pronunciación (o gráficamente) de una $\mathbf{n}$ final. Es una idea a explorar. De esta manera podríamos intentar explicar ean respecto a ea, por más que desde un punto de vista morfológico resulta complicado explicar que una fórmula aparentemente igual permita una morfología diversa. Esto se podría intentar asociar a las variantes de naŕken diciendo que la auténtica variación es naŕke / naŕken y que detrás habría un límite de palabra (así sería naŕken ii, naŕken ai, naŕken ti y naŕken $\mathbf{p i}^{\mathbf{i}^{45}}$ ) y relacionando las formas ean y baren; pero la escasísima frecuencia de esta última variante hace que quede como una anomalía. El principal problema de esta solución es que implica que las diversas irregularidades, como la frecuencia de -np(y en especial la alternancia de uarnpan), serían casualidades; es decir, que es una "solución» que va en contra de los indicios. En todo caso, no es imposible que uarnpan sean dos palabras (podrían aducirse algunos apoyos a la idea), pero dista de ser obvio.

En conjunto considero que la hipótesis morfológica, aun siendo digna de ulterior consideración, con los datos actuales no parece recomendable. Mientras que la eventualidad de que hubiese una caída de la $\mathbf{n}$ (gráfica o fonética) tiene el serio problema metodológico de ser difícilmente falsable (resultando un $a d h o c$ ) y el que el principal criterio de falsabilidad que se le puede aplicar aboga en su contra; puesto que el fenómeno no se reproduce en los típicos finales de los onomásticos en -on.

44 Posibilidades alternativas pueden plantearse a partir del hecho de que exista un signo sobrante también para a (sea $\boldsymbol{\$}$ o $\}$ ). Dejando de momento de lado la alternativa de que en realidad tengamos una $/ \mathrm{h} /$, de un lado tenemos el hecho de que la gran frecuencia de $\boldsymbol{\xi}$ hace poco verosímil que fuese un signo $\mathbf{m}$ originario (como ya se ha explicado), mientras que de otro, suponer que $\mathbf{\$}$ fuese un añadido posterior al sistema plantea problemas difíciles. Suponer que substituyera a pa dejando a un pa presuntamente originario $\}$ la función de ma, aunque nos arreglara el problema de su aparición en íbero meridional como be, choca frontalmente con el que no se usa nunca para los términos formulares y deja la incómoda pregunta de ¿por qué habría de substituir al otro? De otro lado, suponer que en realidad $\mathbf{\$}$ fuese la innovación para ma no está exento de ventajas, pero resulta difícil justificar la forma escogida.

45 Independientemente de lo tratado aquí, debo reconocer que no parece ninguna mala solución, sino una explicación plausible a la gran variedad, por mucho que haga infelices a los que se empeñan en considerar que por fuerza han de ser desinencias verbales indoeuropeas. 
De esta manera vemos que para las alternancias np / $\mathbf{p}$ no hay una solución plenamente satisfactoria. Da la impresión de que se trata de un recurso gráfico para señalar una diferencia fonética y que probablemente sea para indicar la nasal labial, pero en la fase actual de las investigaciones lo realmente importante es definir que el problema existe, delimitarlo y ver que se le ha de encontrar una solución satisfactoria. Como partimos de una documentación tan exigua, siempre corremos el peligro de que los indicios más tajantes (tanto a favor, como especialmente en contra de una idea) puedan ser simplemente una errata. Solo nuevas inscripciones aclararán cuál es el indicio bueno y cuál el erróneo.

\section{BibLIOGRAFÍA}

Aguilar SÁEnz, A. et alii, 1992-1993, «La ciudad antigua de Lacimurga y su entorno rural», Studia historica. Historia antigua 10-11, 109-130.

Almagro-Gorbea, M., 2008, "Medellín-Conisturgis: Reinterpretación Geográfica del Suroeste de Iberia», Boletim da Sociedade de Geografia de Lisboa, serie 126. ${ }^{a}$, n. ${ }^{\circ} 1-12,84-115$.

Aubet Semmler, M.a E., 1987, Tiro y las colonias fenicias de Occiente, Bellaterra.

-,1994, Tiro y las colonias fenicias de Occiente. Edición ampliada y puesta al día, Barcelona.

Correa, J. A., 1987, «El signario tartesio», Veleia 2-3, 275-284.

—, 1989, «El origen de la escritura paleohispánica» en: J. González (ed.), Estudios sobre Urso, Sevilla, 281-302.

—, 1990, «La epigrafía del Suroeste», Arqueologia Hoje 1. Etno-Arqueologia, 132-143.

—, 1992, "La epigrafía tartesia» en: J. Untermann, D. Hertel (eds.), Andalusien zwischen Vorgeschichte und Mittelalter 'Forum Ibero-Americanum'7, Köln, 75-114.

—,2002, "La distribución de las oclusivas orales en la toponimia prerromana de la Bética», Palaeohispanica 2, 133-139.

Correia, V. H., 1996, A epigrafia da Idade do Ferro do Sudoeste da Peninsula Ibérica, Porto.

García-Bellido, M.a P., 2013, «¿Clerujías cartaginesas en Hispania? El caso de Lascuta», Palaeohispanica $13,301-322$.

Guerra, A., 2002, «Novos documentos epigrafados com escrita do Sudoeste da vertente setentrional da Serra do Caldeirao", RPA 5/2, 219-231.

—,2013, «Algumas questôes sobre as escritas pré-romanas do Sudoeste hispânico», Palaeohispanica 13, 323-345.

Guerra, A. et alii, 1999, «Uma estela epigrafada da Idade do Ferro, proveniente do Monte Novo do Castelinho (Almodôvar)», RPA 2/1, 143-152.

De Hoz, J., 1985, «El origen de la escritura del S.O.» en: Actas del III Coloquio sobre Lenguas y Culturas Paleohispánicas, Salamanca, 423-464.

—,1989, «El desarrollo de la escritura y las lenguas en la zona meridional», en: M.a E. Aubet (ed.), Tartessos. Arqueología protohistórica del Bajo Guadalquivir, 523-587.

—,1990, «El origen oriental de las antiguas escrituras hispanas y el desarrollo de la escritura del Algarve», en: Presenças Orientalizantes no Território Português até à Epoca Romana, Lisboa, 219-246.

—,2010, Historia lingüistica de la Peninsula Ibérica en la Antigüedad. I. Preliminares y mundo meridional prerromano, CSIC, Madrid.

Jagersma, A., 2000, «Sound change in Sumerian: the so-called /dr/-phoneme», Acta Sumerologica 22, 81-87.

Koch J.T., 2011, Tartessian 2, Aberystwyth.

Krahmalkov, Ch., 2001, A Phoenician-Punic Grammar, Leiden.

Laver, J., 1994, Principles of Phonetics, CUP Melbourne.

Loprieno, A., 1995, Ancient Egyptian. A linguistic introduction, CUP, Melbourne. 
Miknailova, T. A., 2010, «J.T. Koch. Tartessian: Celtic in the South-West at the Dawn of history (Celtic Studies Publication XIII). Aberystwyth: Centre for advanced Welsh and Celtic studies, 2009", Bonpocbl языкознания 3, 140-145.

Rodríguez Ramos, J., 1992, [inédito]: Análisis de Epigrafía Sudlusitana, tesis de licenciatura, Universidad de Barcelona.

—,2000a, «La lectura de las inscripciones sudlusitano-tartesias», Faventia 22/1, 21-48.

—,2000b, «Sobre la geminación gráfica de signos vocálicos en la escritura sudlusitano-tartesia», Veleia 17, 147-152.

—, 2001, «La cultura ibérica desde la perspectiva de la epigrafía: un ensayo de síntesis», Iberia 4, 17-38.

—,2002a, "Las inscripciones sudlusitano-tartesias, su función, lengua y contexto socio-económico», Complutum 13, 85-95.

—,2002b, «El origen de la escritura sudlusitano-tartesia y la formación de alfabetos a partir de alefatos», RStFen XXX,2, 187-222.

—,2004, Análisis de Epigrafía Íbera [Anejos de Veleia. Series Minor 22], Vitoria-Gasteiz.

—,2005-2009, "La lengua sudlusitana», Studia Indogermanica Eodziensia VI, 83-108.

SÁez Fernández, P., 1990, "Estudio sobre una inscripcion catastral colindante con Lacimurga», Habis 21, 205-227.

SChMOLL, U., 1961, Die südlusitanischen Inschriften, Wiesbaden.

Toscano Pérez, C., Correa Rodríguez, J. A., 2014, "Grafitos tartesios hallados en Niebla (Huelva) y su contexto arqueológico", Onoba 2, 45-54.

Untermann, J., 1997, Monumenta Linguarum Hispanicarum. Bd. IV, Die tartessischen, keltiberischen und lusitanischen Inschriften, Wiesbaden.

VAlerio, M., 2008, «Origin and development of the Paleohispanic scripts: The Orthography and Phonology of the Southwestern Alphabet», RAP 11/2, 107-138. 
Anexo

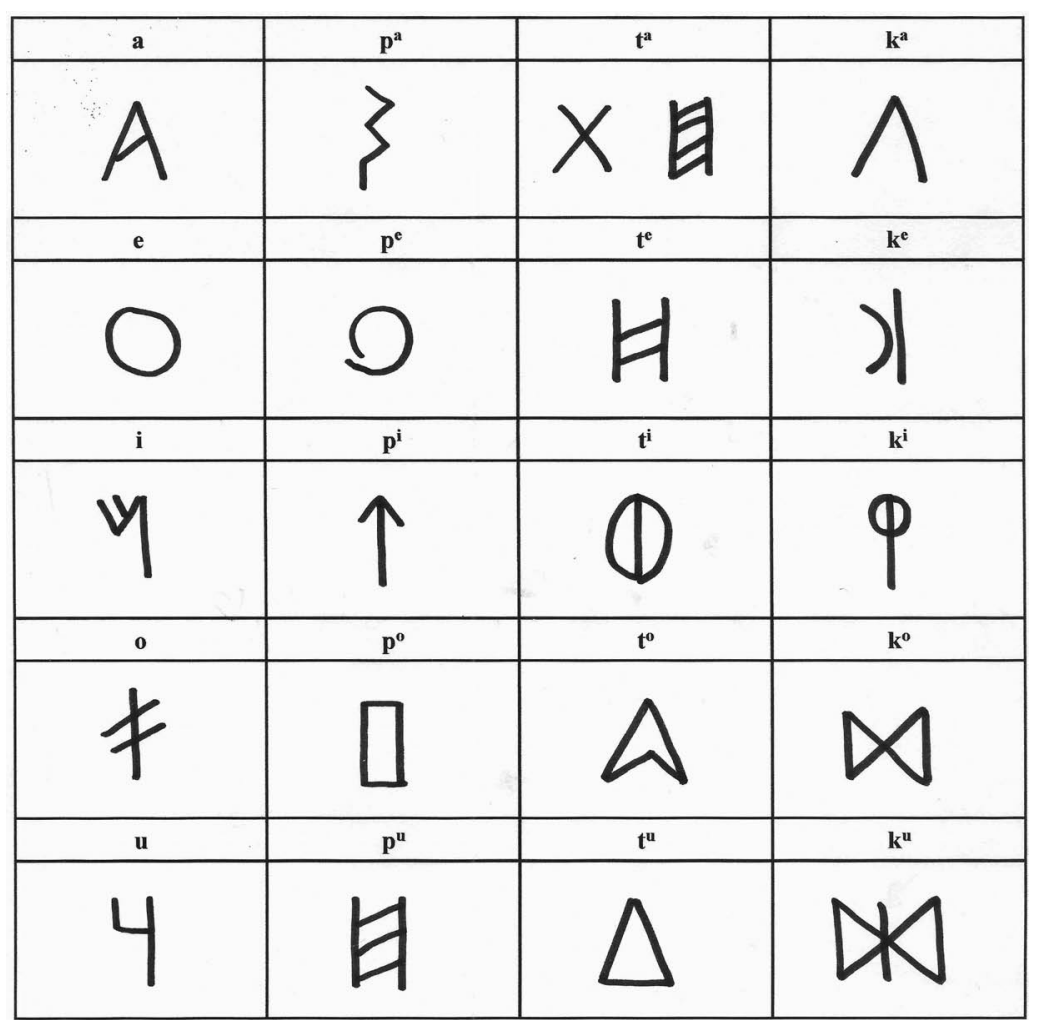

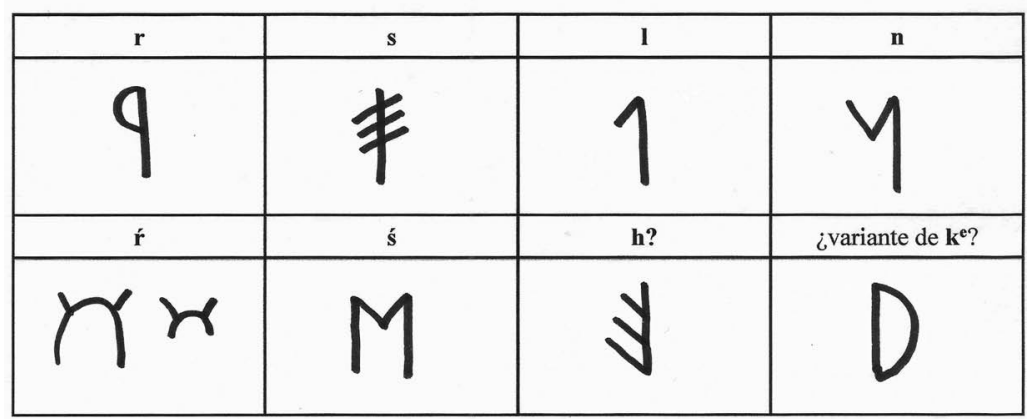

Tabla I. Signario Tartésico Monumental: cuadro resumen (signos estandarizados en dirección sinistrorsa)

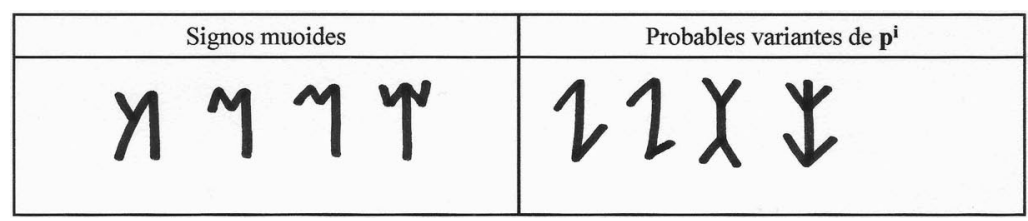

TABla 2. Signos «muoides» y signos que posiblemente son variantes de pi. 


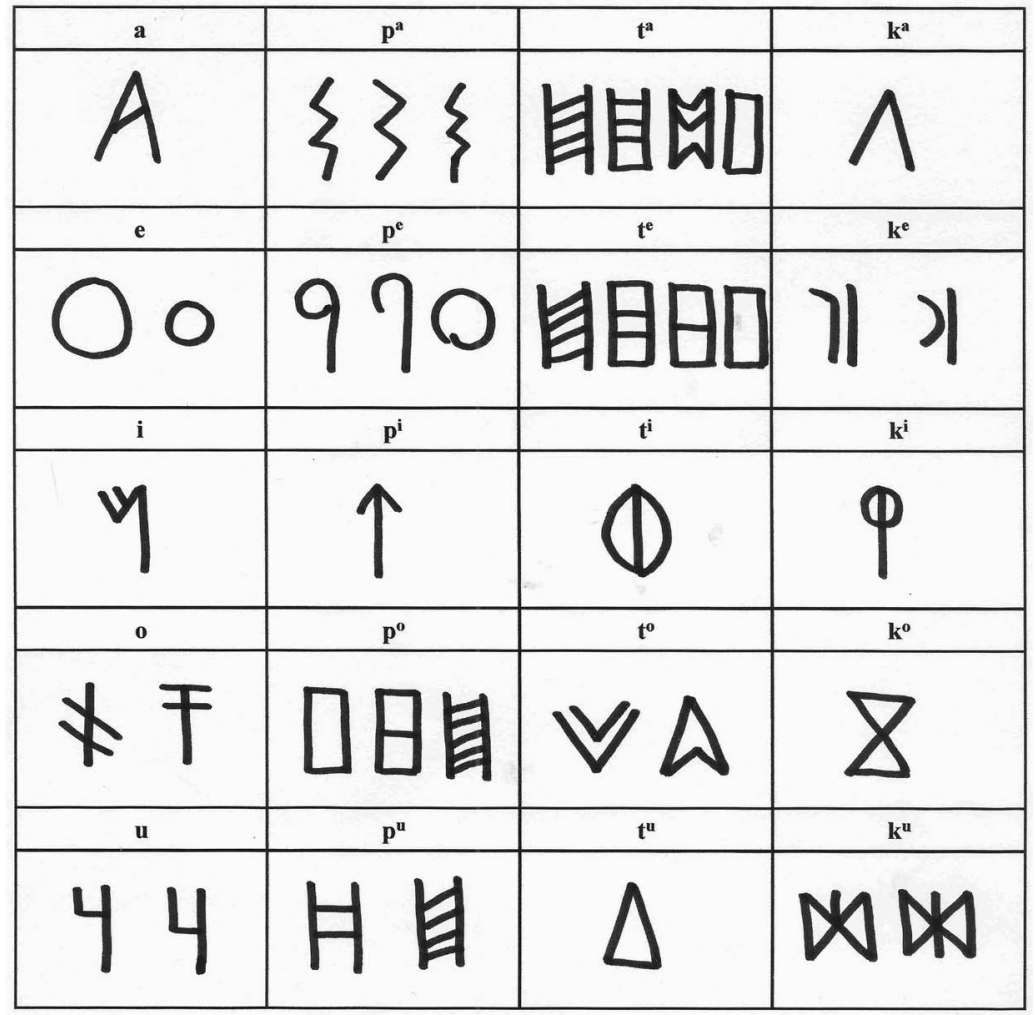

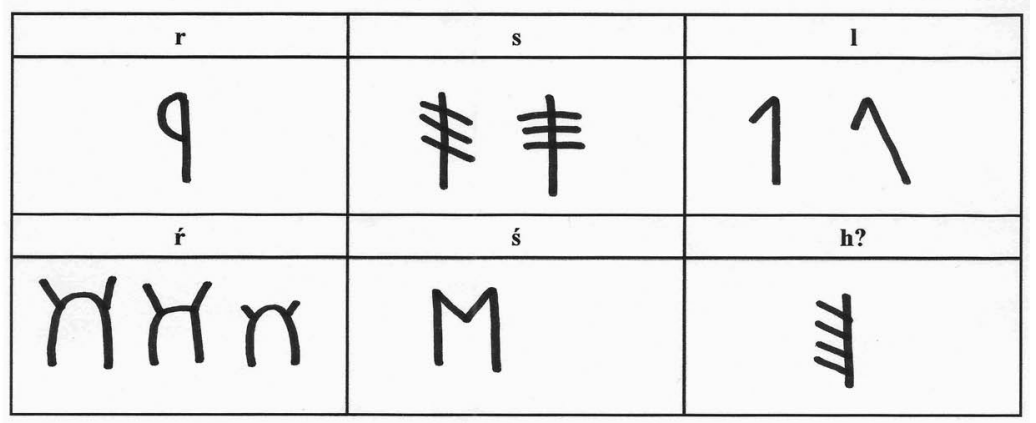

Tabla 3. Cuadro del Signario Tartésico Monumental ilustrativo de las formas más caracteristicas de la variante algarveña (signos estandarizados en dirección sinistrosa) 


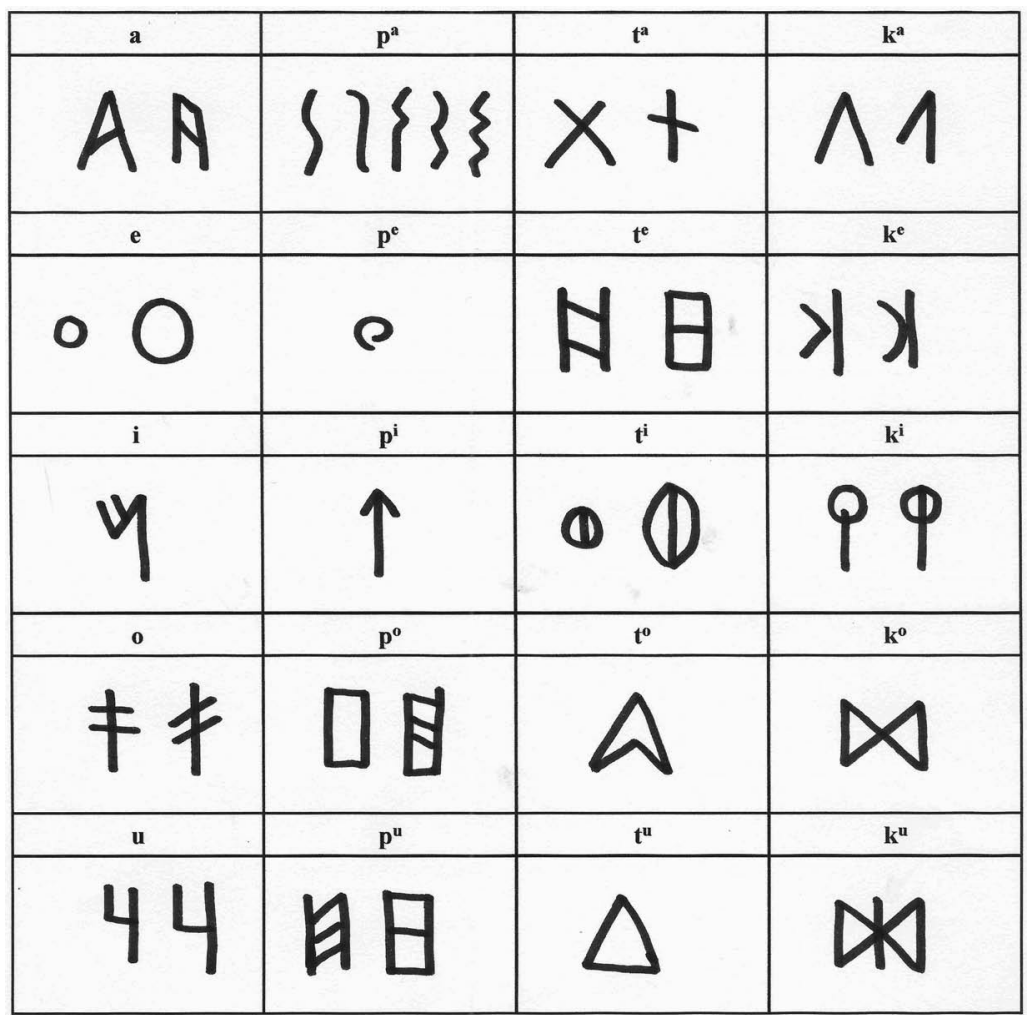

\begin{tabular}{|c|c|c|}
\hline r & s & 1 \\
\hline $\mathrm{y}$ & $\neq \pm$ & 1 \\
\hline $\mathrm{r}$ & $\mathrm{s}$ & $\mathrm{n}$ \\
\hline
\end{tabular}

Tabla 4. Cuadro del Signario Tartésico Monumental destacando las formas más características de las inscripciones que no corresponden a la variante algarveña (signos estandarizados en dirección sinistrosa). No corresponde a un grupo paleográfico único pero sirve para resaltar las diferencias respecto al algarveño 